Article

\title{
Characterizing the Absorption Properties for Remote Sensing of Three Small Optically-Diverse South African Reservoirs
}

\author{
Mark William Matthews ${ }^{1, *}$ and Stewart Bernard ${ }^{1,2}$ \\ ${ }^{1}$ Marine Remote Sensing Unit, Department of Oceanography, University of Cape Town, Rondebosch, \\ 7701 Cape Town, South Africa \\ ${ }^{2}$ Earth Systems Earth Observation, Council for Scientific and Industrial Research, 15 Lower Hope \\ Street, Rosebank, 7700 Cape Town, South Africa; E-Mail: sbernard@ csir.co.za \\ * Author to whom correspondence should be addressed; E-Mail: mttmar017@myuct.ac.za; \\ Tel.: +27-216-505-775.
}

Received: 16 July 2013; in revised form: 30 August 2013 / Accepted: 3 September 2013 /

Published: 9 September 2013

\begin{abstract}
Characterizing the specific inherent optical properties (SIOPs) of water constituents is fundamental to remote sensing applications. Therefore, this paper presents the absorption properties of phytoplankton, gelbstoff and tripton for three small, optically-diverse South African inland waters. The three reservoirs, Hartbeespoort, Loskop and Theewaterskloof, are challenging for remote sensing, due to differences in phytoplankton assemblage and the considerable range of constituent concentrations. Relationships between the absorption properties and biogeophysical parameters, chlorophyll- $a$ (chl- $a$ ), TChl (chl- $a$ plus phaeopigments), seston, minerals and tripton, are established. The value determined for the mass-specific tripton absorption coefficient at $442 \mathrm{~nm}, a_{t r}^{*}(442)$, ranges from 0.024 to $0.263 \mathrm{~m}^{2} \cdot \mathrm{g}^{-1}$. The value of the TChl-specific phytoplankton absorption coefficient $\left(a_{\phi}^{*}\right)$ was strongly influenced by phytoplankton species, size, accessory pigmentation and biomass. $a_{\phi}^{*}(440)$ ranged from 0.056 to $0.018 \mathrm{~m}^{2} \cdot \mathrm{mg}^{-1}$ in oligotrophic to hypertrophic waters. The positive relationship between cell size and trophic state observed in open ocean waters was violated by significant small cyanobacterial populations. The phycocyanin-specific phytoplankton absorption at $620 \mathrm{~nm}, a_{p c}^{*}(620)$, was determined as $0.007 \mathrm{~m}^{2} \cdot \mathrm{g}^{-1}$ in a $M$. aeruginosa bloom. Chl- $a$ was a better indicator of phytoplankton biomass than phycocyanin (PC) in surface scums, due to reduced accessory pigment production. Absorption budgets demonstrate that monospecific blooms of $M$. aeruginosa and $C$. hirundinella may be treated as "cultures", removing some complexities for remote sensing applications. These results contribute toward a better
\end{abstract}


understanding of IOPs and remote sensing applications in hypertrophic inland waters. However, the majority of the water is optically complex, requiring the usage of all the SIOPs derived here for remote sensing applications. The SIOPs may be used for developing remote sensing algorithms for the detection of biogeophysical parameters, including chl- $a$, suspended matter, tripton and gelbstoff, and in advanced remote sensing studies for phytoplankton type detection.

Keywords: remote sensing; inherent optical properties; inland waters; absorption; phycocyanin; tripton; phytoplankton; South Africa

\section{Introduction}

Knowledge of the inherent optical properties (IOPs), including the absorption of phytoplankton, gelbstoff (or chromophoric dissolved organic matter) and tripton (non-living minerals and detritus), is critical to water remote sensing. IOPs are required for remote sensing algorithm development and for physically-based bio-optical models simulating the behavior of light in water (e.g., [1]). Physically-based water constituent retrieval remote sensing algorithms, especially those targeting specific water types or classes, rely heavily on IOPs, as do biogeochemical models. As a result, much attention has been given to determining the variability in the absorption properties of coastal and open-ocean marine waters (e.g., [2-4]). Recent studies have also sought to characterize the absorption properties of optically-complex inland and estuarine waters (e.g., [5-10]). However, there is an ongoing need to investigate the variability that might be encountered across these diverse systems, especially those that are hypertrophic. This poses an ongoing challenge for satellite-based remote sensing applications aimed at characterizing the phenology and ecological state of Earth's precious and vulnerable fresh waters.

In water-scarce South Africa, man-made reservoirs provide an essential source of potable water to a growing urban population. Widespread eutrophication and cyanobacterial blooms have degraded water quality in many of these reservoirs, posing a potential health threat to millions of consumers, as well as for industrial and commercial users [11]. Data on the optical characteristics and variability of these reservoirs is lacking, hindering present and future monitoring efforts using remote sensing. This paper aims to describe the variability in the absorption properties of phytoplankton, gelbstoff and tripton of three optically-diverse South African reservoirs. It describes the relationships between absorption and biogeophysical variables, chlorophyll- $a$ (chl- $a$ ), seston (total suspended solids) and mineral dry weight. The chl- $a$-specific absorption coefficients $\left(a_{\phi}^{*}\right)$ are determined for the diverse phytoplankton assemblages and discussed with reference to typical values reported in Case 1 waters. The variability of the phycocyanin (PC)-specific absorption at $620 \mathrm{~nm}, a_{p c}^{*}(620)$, used in semi-analytical algorithms aimed at the detection of PC (e.g., [12,13]), is also determined for cyanobacterial blooms and in surface scums of Microcystis aeruginosa. The mass-specific tripton absorption coefficients $\left(a_{t r}^{*}\right)$ are determined using a modified technique and the results compared to reported values from inland and coastal waters. Finally, absorption budgets are presented for each of the reservoirs. The aims of 
the paper are to provide a thorough description of the range of variability in absorption properties that might typically be encountered in South African inland waters, and to provide IOPs for use in remote sensing radiative transfer studies and physically-based water constituent retrieval algorithms (see Matthews and Bernard [14]).

Figure 1. The geographical location and shapes of the three reservoirs, Loskop, Hartbeespoort and Theewaterskloof. Sample points are indicated with labeled dots (see text for details).
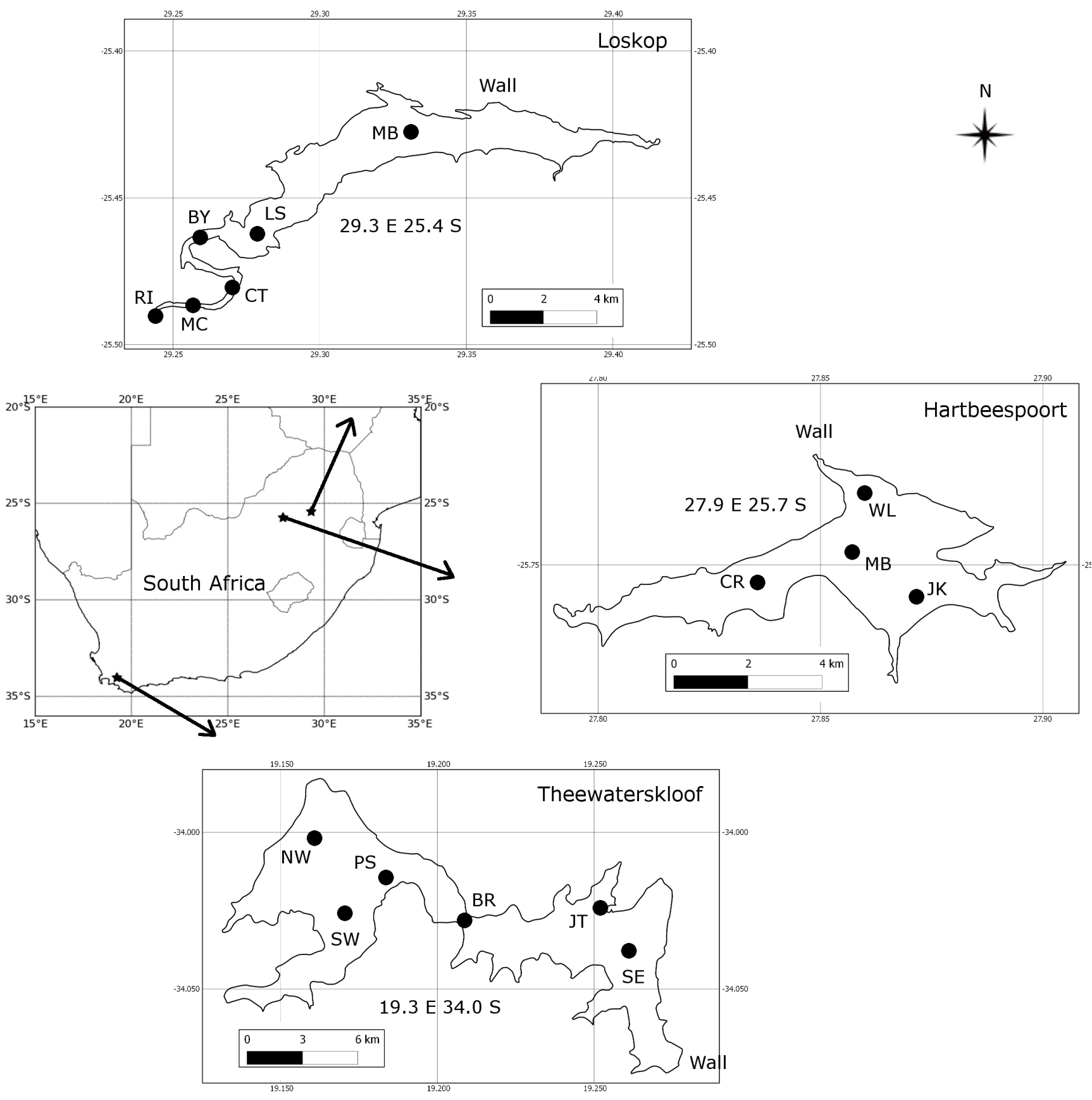


\section{Methods}

\subsection{Study Areas and Sampling Strategy}

The three study areas, Hartbeespoort, Loskop and Theewaterskloof reservoirs, were chosen in order to capture some of the diverse range of water types and blooms occurring in South African inland waters (Figure 1). Sampling campaigns were undertaken at each of the lakes for a three week period: at Hartbeespoort in October 2010, at Loskop in July/August 2011, and at Theewaterskloof in April 2012. Sample points (see Figure 1) were located so as to capture the diversity of water conditions occurring in each of the reservoirs. Surface water samples were collected in $1 \mathrm{~L}$ plastic containers or in $5 \mathrm{~L}$ opaque plastic buckets following thorough rinsing with lake water. Every effort was made to avoid disturbing the dense aggregations of cyanobacteria on the water surface (when present) by gently collecting water into containers held horizontally. Samples were kept in the dark and on ice until analysis. Water clarity was measured using a Secchi disk, $z_{s d}$, using the mean of the depth at which the disk disappeared and then re-appeared.

Of the three study areas, Hartbeespoort is the most extensively studied, followed by Loskop, while Theewaterskloof is almost undescribed in the scientific literature. Detailed information on the limnology and phytoplankton dynamics of Hartbeespoort is available (e.g., [15-17]). It is one of the most productive reservoirs in the world, with so-called hyperscums of Microcystis Aeruginosa [18]. Measurements of its optical properties, however, are limited to light attenuation [19,20]. The water quality and phytoplankton assemblage of Loskop has previously been described [21-23]. Situated on the Olifants River, Loskop has very diverse water types, due to its longitudinal zonation, with pronounced riverine, transitional and lacustrine zones [22]. The water is affected by acid mine drainage and has high concentrations of heavy metals and nutrients (ibid.). However, no detailed limnological study of the reservoir has been undertaken, and information on its light environment is limited to a Secchi disk. Theewaterskloof is located in the western winter rainfall region of South Africa and is one of the primary water supply reservoirs for the Cape Town region through an inter-basin transfer scheme. The reservoir is divided into two basins by a narrow channel crossed by a bridge; the western basin contains the inlet from the Sonderend River and the eastern basin, the dam wall. Despite its great importance as a potable water supply, there is no published information on its limnology, phytoplankton assemblage or light environment.

\subsection{Phytoplankton Pigments}

Water samples were filtered under low pressure $(>10 \mathrm{~mm}$ mercury pressure) through Whatmann GF/F filters on the same day as collection. The concentrations of chl- $a$ and phaeopigments were determined spectrophotometrically using an extraction solution of $90 \%$ boiling ethanol after Sartory and Grobbelaar [24], due to the improved extraction efficiency of ethanol with freshwater phytoplankton assemblages containing cyanobacteria. TChl is defined as the sum of chl- $a$ and phaeopigments. Phycocyanin (PC) and allo-phycocyanin (APC) pigments were measured when cyanobacteria made up a significant portion of the phytoplankton assemblage. Cyanobacteria have very resistant cell walls that must be broken to release the water soluble phycobiliproteins. Various methods 
may be used to break the cell walls, including freezing and thawing [25], enzymatic attack [26], osmotic shock [27], attack by $\mathrm{N}$ fixing bacteria [28], acid, nitrogen cavitation and french press (see [28,29] for details). However, the most efficient methods appear to be freeze-thaw and enzymatic attack [28]. Therefore, a combination of these techniques was used after Beutler [30] to optimize extraction efficiency and to reduce the amount of time required for analysis in the field. Filter papers were frozen for at least $24 \mathrm{~h}$ in $15 \mathrm{~mL}$ screw capped tubes. If samples were being transported, they were stored in liquid nitrogen and, then, at $-70{ }^{\circ} \mathrm{C}$. After thawing, an extraction solution of $0.25 \mathrm{M}$ Trizma Base, $10 \mathrm{mM}$ disodium EDTA (Ethylenediaminetetraacetic acid) and $2 \mathrm{mg} \cdot \mathrm{mL}^{-1}$ lysozyme was added. After grinding with a glass rod, the filter paper was incubated in the dark for $2 \mathrm{~h}$ at $37{ }^{\circ} \mathrm{C}$ and, then, stored in the cold for at least $20 \mathrm{~h}$ to allow for extraction. The samples were then diluted with Milli-Q water and centrifuged at $3,600 \mathrm{~g}$ for $15 \mathrm{~min}$. to reduce turbidity. The supernatant was initially filtered through a $0.2 \mu \mathrm{m}$ pore size membrane filter; however, this may interfere with the phycobiliproteins so subsequent analyses did not filter the supernatant [69]. The sample was read in the spectrophotometer using $1 \mathrm{~cm}$ matched quartz cuvettes using the extraction solution as the reference, and the PC concentration was calculated according to Bennett and Bogorad [31]. All pigment analyses were done in triplicate using the mean as the final value.

\subsection{Seston, Minerals and Tripton Concentrations}

Seston dry mass was determined using pre-ashed Whatmann GF/F filter papers following the gravimetric technique [32]. The inorganic component (here, referred to as minerals) was determined by burning the filter pads in a muffle furnace at $500{ }^{\circ} \mathrm{C}$ and re-weighing. All analyses were done in triplicate using the mean as the final value.

Tripton corresponds to the de-pigmented matter measured by the quantitative filter technique (QFT, see below). However, it is difficult to separate out the living phytoplankton component of seston in order to measure tripton dry mass. Determination of $a_{t r}^{*}$ is useful for bio-optical models, because it allows for the particulate detrital and mineral components to be handled simultaneously and separately from living phytoplankton. Seston dry mass might be partitioned most simply into its tripton and phytoplankton components according to: tripton $=$ seston $-\beta \times$ chla, where $\beta$ is a conversion factor to estimate phytoplankton dry mass from chl- $a$. Most studies using this technique assume a constant value of $\beta$, most often equal to $0.07 \mathrm{~g} \cdot \mathrm{mg}^{-1}$ (e.g., [33-35]). However, the value of $\beta$ varies widely in nature, according to the intracellular chl- $a$ concentration, which is dependent on the species and the light and nutrient environment. For cyanobacteria $P$. hollandica and $O$. limnetica cultured under a range of light and nutrient conditions, Gons et al. [36] determined the value of $\beta$ to range between $0.02-0.3 \mathrm{~g} \cdot \mathrm{mg}^{-1}$, mean $=0.046 \mathrm{~g} \cdot \mathrm{mg}^{-1}$. Zhang et al. [37] determined a value of $0.09 \mathrm{~g} \cdot \mathrm{mg}^{-1}$ for an assemblage dominated by Microcystis and Scenedesmus in lake Taihu, China. Desortová [38] determined that the chl- $a$ content per unit fresh phytoplankton biomass for various lakes was between $0.14 \%$ and $3.41 \%$, which corresponds to a $\beta$ of $0.029-0.71 \mathrm{~g} \cdot \mathrm{mg}^{-1}$. The range of variability was primarily related to seasonal variation in solar radiation, with larger values being attributed to low-light conditions (winter months). Natural populations of individual cells of various species have mean values ranging from 0.0496 to $0.21 \mathrm{~g} \cdot \mathrm{mg}^{-1}$ (calculated from Table 1.3 in [39]). 
In this study, values of $\beta$ were determined by investigating the ratio of phytoplankton to detritus, $R_{p d}$. In steady-state conditions (i.e., loss rate = growth rate), $R_{p d}$ should be constant, irrespective of the trophic state, with a value near 0.3 [36]. This is in agreement with reported values of $R_{p d}$ in lakes, which are typically between $20 \%$ and $35 \%$ (e.g., [40,41]). In non-steady-state conditions, $R_{p d}$ may vary; however, its value is expected to be less than one for almost all growth conditions [36]. The existence or non-existence of steady-state conditions was determined by examining the variability of the chl-a:seston ratio in time [36]. For conditions deemed to be in steady-state, values for $\beta$ were selected where the corresponding $R_{p d}$ values were near 0.3 . On average, phytoplankton contains 10\% mineral content (ash dry mass) [39]. Therefore, detrital dry weight was calculated according to: detritus $=$ seston $-0.9 \times$ minerals $-\beta \times$ chla. $R_{p d}$ was calculated using the detrital and phytoplankton dry mass calculated for a range of $\beta$ values. Since ash dry weight was not determined in Hartbeespoort, minerals were assumed to be zero, which, in this case, might be a reasonable assumption (see results).

\subsection{Absorption Coefficients of Particulate, Pigmented and Dissolved Substances}

The QFT was used to determine the absorption of total particulate matter (seston) and de-pigmented matter (tripton) after Mitchell et al. [42]. Water samples were stored in the dark and analyzed on the same day as collection. The sample was filtered under low vacuum pressure $(>10 \mathrm{~mm}$ mercury pressure) through a pre-ashed Whatman GF/F filter paper pre-washed with Milli-Q water, adjusting the volume according to the turbidity of the sample. In cases of very high biomass, such as Hartbeespoort (chl- $a>10,000 \mathrm{mg} \cdot \mathrm{m}^{-3}$ ), as little as $2.5 \mathrm{~mL}$ was filtered, while for chl- $a<1 \mathrm{mg} \cdot \mathrm{m}^{-3}$ in Loskop, up to $1 \mathrm{~L}$ was filtered to obtain sufficient material on the filter. Blank filter papers were treated identically to the sample, by simultaneously filtering the same volume of Milli-Q water as the sample. Care was taken to not run the blank filters dry. Filter papers were kept in labeled Petri dishes with a drop of water until analysis to ensure hydration.

The optical density (OD) of the particulate and blank filter paper between 350 and $850 \mathrm{~nm}$ was measured using a Shimadzu UV-2501 spectrophotometer using an ISR-2200 integrating sphere. The mean OD of the filter relative to the blank was near 0.5 for all samples. In the case of Hartbeespoort, however, the value was unavoidably higher, owing to the extremely high biomass. The mean OD of the blank measurements was subtracted from the particulate OD measurements and the absorption calculated using a pathlength amplification factor $\beta=2$ [43]. A null subtraction was performed at the highest wavelength of measurement $(=850 \mathrm{~nm})$ as the assumption of no absorption from particulate matter at $750 \mathrm{~nm}$ does not hold in highly turbid inland waters. Duplicate particulate absorption measurements were performed for each sample, using the mean of the two spectra as the final value.

$a_{t r}$ was determined by two methods, sodium hypochloride $(\mathrm{NaClO})$ oxidation and, in the case of Theewaterskloof, boiling methanol extraction. Both of these techniques have been used for freshwater samples (e.g., [9,44]), but little information exists on what quantitative errors each of these methods might introduce. Since both methods remove non-chlorophyllous pigments (carotenoids and phaeopigments), the phytoplankton absorption will tend to be overestimated. The $\mathrm{NaClO}$ technique has two advantages in that it bleaches the water soluble phycobilipigments and resistant cells (e.g., chlorophytes), and it may be performed more rapidly in the field [45]. However, there is some evidence 
to suggest that $\mathrm{NaClO}$ treatment of samples with high dissolved organic matter may cause bleaching of colloidal/particle-bound organic matter, leading to overestimates of phytoplankton absorption in the blue spectrum [9]. Furthermore, $\mathrm{NaClO}$ is unsuitable for waters with a high abundance of heterotrophic bacteria, due to the production of a yellow cytochrome byproduct deposited on the filter [46]. Techniques using organic solvents methanol or ethanol (e.g., [12]) might avoid these effects, although it is uncertain to what degree phycobilipigments are removed, even when related absorption peaks are not visible in the absorption spectrum. Measurements were performed using both techniques in order to quantify and elucidate these errors. Complete pigment bleaching/extraction was assessed by the absence of the $675 \mathrm{~nm}$ chl- $a$ absorption peak. In cases of insufficient bleaching/extraction, the filter paper was gently subjected to further bleaching/extraction until the $675 \mathrm{~nm}$ peak disappeared. The filters were thoroughly rinsed with Milli-Q water to remove contamination by $\mathrm{NaClO}$ in order to perform readings $<400 \mathrm{~nm}$. Blank filter papers were treated identically to samples. The mean bleached blank OD was subtracted from the bleached particulate OD to calculate the tripton absorption. The tripton absorption curves were fitted to an exponential function [47], and the slope coefficient, $S_{t r}$, was computed using a reference wavelength of $442 \mathrm{~nm}$.

The phytoplankton absorption component was then computed as $a_{\phi}=a_{p}-a_{t r}$. The specific absorption coefficients, $a_{\phi}^{*}$ and $a_{t r}^{*}$, were determined by dividing $a_{\phi}$ and $a_{t r}$ by the concentration of TChl and tripton, respectively. In order to calculate the PC-specific absorption coefficient, $a_{p c}^{*}(620)$, a correction needs to be applied to $a_{\phi}(620)$ in order to remove the effect of residual chl- $a$ absorption, termed $a_{c h l}(620)$. Simis et al. [12] determined the value of $a_{c h l}(620)$ from $a_{\phi}(665)$ using a ratio term, $\epsilon=0.24$. The absorption exclusively due to PC is then calculated by $a_{p c}(620)=a_{\phi}(620)-\epsilon \times a_{\phi}(665)$. $a_{p c}^{*}(620)$ is then calculated by $a_{p c}(620) / P C$. The value of $\epsilon$ determined by Simis $e t a l$. [12] is generally suitable for use in cyanobacteria-dominated waters and, therefore, is used here. No attempt was made to correct for algae containing other pigments influencing absorption near 665 and $620 \mathrm{~nm}$ (e.g., [48]). The absorbance due to gelbstoff, $a_{g}$, was read between 340 and $750 \mathrm{~nm}$ in the spectrophotometer using matched $10 \mathrm{~cm}$ quartz cuvettes using room temperature Milli-Q water as the reference. A null-point correction at $750 \mathrm{~nm}$ was implemented and the absorption calculated according to Mitchell et al. [42]. The curves were fitted to an exponential function [47] between 350 and $500 \mathrm{~nm}$, and the slope coefficient, $S_{g}$, was computed using a reference wavelength of $442 \mathrm{~nm}$.

\section{Results and Discussion}

\subsection{General Characteristics of Reservoirs}

There was extremely large variability in biogeochemical and optical parameters between and within the three systems studied (Table 1). Figure 2 shows scatter plots of some parameters illustrating this variability, and the correlation coefficients for the entire dataset are shown in Table 2. Chl- $a$ and seston are highly correlated $(r=0.92)$, with concentrations varying over six and five orders of magnitude, respectively (Figure 2A). The extremely high chl- $a$ values $>1,000 \mathrm{mg} \cdot \mathrm{m}^{-3}$ were measured in surface scum conditions in Hartbeespoort. The greatest trophic range is found in Loskop, with chl- $a$ varying from 0.5 to $500 \mathrm{mg} \cdot \mathrm{m}^{-3}$, while Theewaterskloof has the least range. The organic component of seston, 
calculated as the difference between seston and minerals, is highly correlated with chl- $a$ ( $r=0.85$, Figure 2B). Weak correlations between gelbstoff absorption at $442 \mathrm{~nm}, a_{g}(442)$, and chl- $a$ and seston are apparent ( $r=0.63$ and 0.54 , respectively, Figure 2C,D). However, the considerable scatter implies that the relationship is reservoir-specific and that $a_{g}$ is largely controlled by catchment-related factors, rather than phytoplankton biomass or seston [49]. Water clarity $\left(z_{s d}\right)$ is inversely correlated to seston $(r=-0.43)$ and its mineral and organic components and phytoplankton pigments (chl- $a, r=-0.27$, Figure 2E,F). These relationships might be applied between reservoirs, given the general inverse trend.

Table 1. Variability in biogeophysical and optical parameters for each reservoir. Chl-a, chlorophyll- $a$.

\begin{tabular}{|c|c|c|c|c|c|c|c|c|c|c|c|c|}
\hline & $\underset{\mathrm{mg} \cdot \mathrm{m}^{-3}}{\mathrm{Chl}-a}$ & $\begin{array}{c}\mathrm{PC} \\
\mathrm{mg} \cdot \mathrm{m}^{-3}\end{array}$ & $\begin{array}{c}\text { Seston } \\
\mathrm{g} \cdot \mathrm{m}^{-3}\end{array}$ & $\begin{array}{l}\text { Minerals } \\
\mathbf{g} \cdot \mathbf{m}^{-3}\end{array}$ & $\begin{array}{c}z_{s d} \\
\mathbf{c m}\end{array}$ & $\begin{array}{c}\text { TChl } \\
\mathrm{mg} \cdot \mathrm{m}^{-3}\end{array}$ & $\begin{array}{c}a_{g}(442 \mathrm{~nm}) \\
\mathbf{m}^{-1}\end{array}$ & $\underset{\mathrm{nm}}{S_{g}}$ & $\begin{array}{c}a_{p}(442 \mathrm{~nm}) \\
m^{-1}\end{array}$ & $\begin{array}{c}a_{t r}(442 \mathrm{~nm}) \\
\mathrm{m}^{-1}\end{array}$ & $\begin{array}{c}S_{t r} \\
\mathrm{~nm}^{-1}\end{array}$ & $\begin{array}{c}a_{\phi}(442 \mathrm{~nm}) \\
m^{-1}\end{array}$ \\
\hline \multicolumn{13}{|c|}{ Hartbeespoort } \\
\hline Min. & 33.0 & 84.3 & 6.0 & - & 1.0 & 38.9 & 0.63 & 0.014 & 2.03 & 0.07 & 0.0092 & 1.73 \\
\hline Max. & $25,978.3$ & $43,143.9$ & $2,100.0$ & - & 201.0 & $2,8466.6$ & 4.13 & 0.021 & 456.24 & 1.74 & 0.0098 & 455.32 \\
\hline Mean & $3,872.6$ & $4,462.9$ & 573.1 & - & 61.9 & $4,260.8$ & 1.55 & 0.017 & 87.48 & 0.51 & 0.0095 & 86.98 \\
\hline St. dev. & $5,703.3$ & $8,225.8$ & 685.4 & - & 51.8 & $6,208.0$ & 0.77 & 0.002 & 133.16 & 0.47 & 0.0004 & 132.83 \\
\hline Median & $1,503.3$ & $1,190.7$ & 225.0 & - & 61.0 & $1,599.3$ & 1.30 & 0.017 & 27.97 & 0.39 & 0.0095 & 27.61 \\
\hline $\mathrm{N}$ & 39 & 39 & 35 & - & 39 & 39 & 34 & 34 & 19 & 19 & 2 & 19 \\
\hline \multicolumn{13}{|c|}{ Loskop } \\
\hline Min. & 0.5 & 25.1 & 0.9 & 0.0 & 37.5 & 1.3 & 0.75 & 0.013 & 0.16 & 0.10 & 0.0078 & 0.05 \\
\hline Max. & 512.9 & 73.5 & 48.9 & 5.7 & 870.0 & 856.3 & 1.87 & 0.022 & 12.58 & 1.57 & 0.0126 & 11.12 \\
\hline Mean & 86.7 & 49.3 & 9.5 & 1.5 & 263.5 & 151.8 & 1.11 & 0.017 & 2.07 & 0.53 & 0.0103 & 1.56 \\
\hline St. dev & 139.5 & 34.2 & 11.3 & 1.5 & 203.8 & 245.3 & 0.24 & 0.002 & 2.72 & 0.39 & 0.0013 & 2.43 \\
\hline Median & 10.1 & 49.3 & 3.3 & 0.9 & 224.0 & 20.6 & 1.07 & 0.017 & 0.62 & 0.42 & 0.0102 & 0.29 \\
\hline $\mathrm{N}$ & 48 & 2 & 55 & 55 & 56 & 49 & 57 & 57 & 57 & 57 & 57 & 56 \\
\hline \multicolumn{13}{|c|}{ Theewaterskloof } \\
\hline$\overline{\text { Min. }}$ & 5.1 & 8.1 & 7.1 & 3.2 & 45.0 & 6.9 & 1.22 & 0.012 & 1.13 & 0.51 & 0.0084 & 0.41 \\
\hline Max. & 69.7 & 70.3 & 29.1 & 22.8 & 108.0 & 118.4 & 2.49 & 0.015 & 3.65 & 2.26 & 0.0130 & 2.43 \\
\hline Mean & 22.2 & 20.4 & 16.4 & 9.3 & 68.2 & 34.7 & 1.85 & 0.014 & 2.07 & 1.18 & 0.0098 & 0.89 \\
\hline St. dev. & 16.3 & 15.1 & 6.0 & 4.6 & 17.7 & 25.5 & 0.45 & 0.001 & 0.72 & 0.44 & 0.0011 & 0.49 \\
\hline Median & 16.3 & 14.9 & 16.4 & 8.0 & 66.0 & 23.0 & 1.86 & 0.014 & 2.18 & 1.05 & 0.0095 & 0.74 \\
\hline $\mathrm{N}$ & 33 & 19 & 32 & 32 & 33 & 33 & 19 & 19 & 19 & 19 & 19 & 19 \\
\hline
\end{tabular}

During the sampling period, $M$. aeruginosa composed more than $90 \%$ of the phytoplankton assemblage in Hartbeespoort (see Table 3). Bright green surface accumulations (10-50 cm thick) were present over most of the lake surface area. The concentration of chl- $a$ and phycocyanin pigments were extremely high (up to 26,000 and $43,000 \mathrm{mg} \cdot \mathrm{m}^{-3}$, respectively). In Loskop, the dinoflagellate, Ceratium hirundinella, is dominant throughout the reservoir in terms of biovolume, although cyanobacteria (in isolated blooms) and other species may be abundant (Figure 3B, Table 3). Working upstream, the main basin (point MB) is typically oligotrophic (chl- $a<1$ ) and very clear, with a mixed population of diatoms, chlorophytes and dinoflagellates. The lacustrine zone (point LS) is oligotrophic (chl- $a<10$ ), with slightly decreased water clarity. The transitional zone where a bio-optical buoy was moored (point BY) is more variable, due to mixing $(1<\operatorname{chl}-a<30)$. A dense bloom of the large-celled dinoflagellate C. hirundinella was present at point CT (Ceratium), turning the water dark brown, with chl- $a$ values in excess of $200 \mathrm{mg} \cdot \mathrm{m}^{-3}$. C. hirundinella blooms are common in South African reservoirs, causing a nuisance for water treatment [50,51]. A dense bright green surface bloom of $M$. aeruginosa was present further upstream at point MC (Microcystis). In summer, as water temperatures rise, the cyanobacteria become more abundant, and blooms extend downstream towards the transitional zone [22]. It appears that $M$. aeruginosa and $C$. hirundinella are competing species in the riverine zone. The inlet of the Olifants River at point RI (river input) is clear, with chlorophytes and diatoms being present. Loskop is, therefore, extremely diverse from both a trophic and color perspective. 
Figure 2. Scatter plots for (A) seston versus chl- $a$; (B) organic matter versus chl- $a$; $(\mathbf{C})$ $a_{g}(442)$ versus chl- $a$; (D) $a_{g}(442)$ versus seston; $(\mathbf{E}) z_{s d}$ versus seston; and (F) $z_{s d}$ versus chl- $a$. Note logarithmic scales.
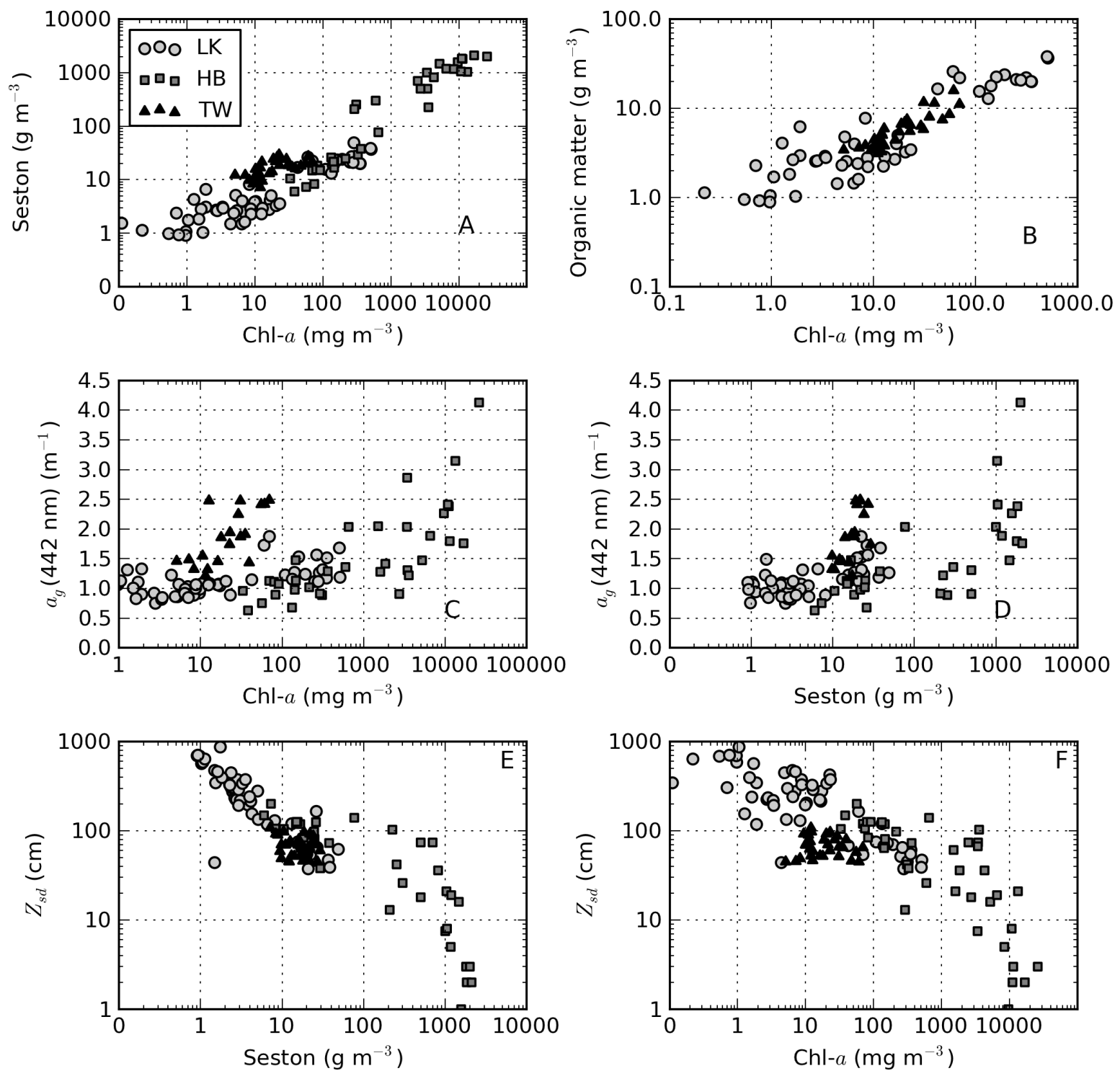

Table 2. Pearson correlation coefficients for entire dataset. The variables are non-normally distributed. PC, phycocyanin; TChl, chl- $a$ plus phaeopigments.

\begin{tabular}{lcccccccc}
\hline & chl- $\boldsymbol{a}$ & PC & Seston & Minerals & Organic Matter & $\boldsymbol{z}_{\boldsymbol{s} \boldsymbol{d}}$ & $\boldsymbol{a}_{\boldsymbol{g}}(440)$ & TChl \\
\hline chl- $a$ & 1 & & & & & & & \\
PC & 0.86 & 1.00 & & & & & & \\
Seston & 0.92 & 0.68 & 1.00 & & & & & \\
Minerals & -0.10 & -0.21 & 0.57 & 1.00 & & & & \\
Organic matter & 0.85 & 0.88 & 0.88 & 0.13 & 1.00 & & & \\
$z_{s d}$ & -0.27 & -0.43 & -0.31 & -0.52 & -0.47 & 1.00 & & \\
$a_{g}(440)$ & 0.63 & 0.67 & 0.54 & 0.76 & 0.34 & -0.43 & 1.00 & \\
TChl & 1.00 & 0.87 & 0.92 & -0.12 & 0.84 & -0.28 & 0.64 & 1.00 \\
\hline
\end{tabular}


Theewaterskloof is more uniform and turbid, with a mixed phytoplankton assemblage (Table 3) and a high mineralic component of dry weight (Table 1). The reservoir is affected by strong prevailing SE and NW winds (gusts up to $7.5 \mathrm{~m} \cdot \mathrm{s}^{-1}$ were measured), which means it is generally well-mixed. Blooms of filamentous cyanobacteria Anabaena ucrainica and a high abundance of diatom species, in particular, Aulacoseira ambigua and Asterionella formosa, are characteristic for the lake. The high mineralic component of dry weight might be related to the presence of these diatom species, which contain $>40 \%$ ash weight of dry weight [39].

Table 3. Predominant phytoplankton species present in this study $\left(>5,000\right.$ cells $\left.\cdot \mathrm{L}^{-1}\right)$. HB, Hartbeespoort; LK, Loskop; TW, Theewaterskloof; p, present.

\begin{tabular}{|c|c|c|c|c|c|c|c|}
\hline & HB & $\mathbf{L K}$ & TW & & HB & LK & TW \\
\hline Bacillariophyceae & & & & Scenedesmus acutiformis & & & $\mathrm{p}$ \\
\hline Melosira varians & & $\mathrm{p}$ & & Cyanophyceae & & & \\
\hline Fragilaria crotonensis & & $\mathrm{p}$ & & Microcystis aeruginosa & $\mathrm{p}$ & $\mathrm{p}$ & $\mathrm{p}$ \\
\hline Fragilaria crotonensis & & $\mathrm{p}$ & & Microcystis aeruginosa & $\mathrm{p}$ & $\mathrm{p}$ & $\mathrm{p}$ \\
\hline Aulacoseira granulate & & $\mathrm{p}$ & & Anabaena ucrainica & & & $\mathrm{p}$ \\
\hline Diatoma vulgaris & & $\mathrm{p}$ & & Dinophyceae & & & \\
\hline Asterionella formosa & & & $\mathrm{p}$ & Ceratium hirundinella & & $\mathrm{p}$ & \\
\hline Aulacoseira ambigua & & & $\mathrm{p}$ & Peridium bipes & & $\mathrm{p}$ & \\
\hline Navicula capitatoradiata & & & $\mathrm{p}$ & Sphaerodinium fimbriatum & & & $\mathrm{p}$ \\
\hline Chlorophyceae & & & & Euglenophyceae & & & \\
\hline Coelastrum reticulatum & & $\mathrm{p}$ & & Trachelomonas volvocina & & $\mathrm{p}$ & \\
\hline Pandorina morum & & $\mathrm{p}$ & & Cryptophyceae & & & \\
\hline Staurastrum paradoxum & & & $\mathrm{p}$ & Cryptomonas ovata & & $\mathrm{p}$ & \\
\hline
\end{tabular}

Figure 3. Mean biovolume (left-most bar) and abundance (center bar) of phytoplankton by group, and $z_{s d}$ (right-most bar) for sample points in (A) Theewaterskloof and (B) Loskop. The legend is the same in A and B. Cyanophyceae count for Loskop point MC has been scaled by a factor of $0.1 . z_{s d}$ is also scaled by a factor of 0.1 in $\mathrm{B}$.
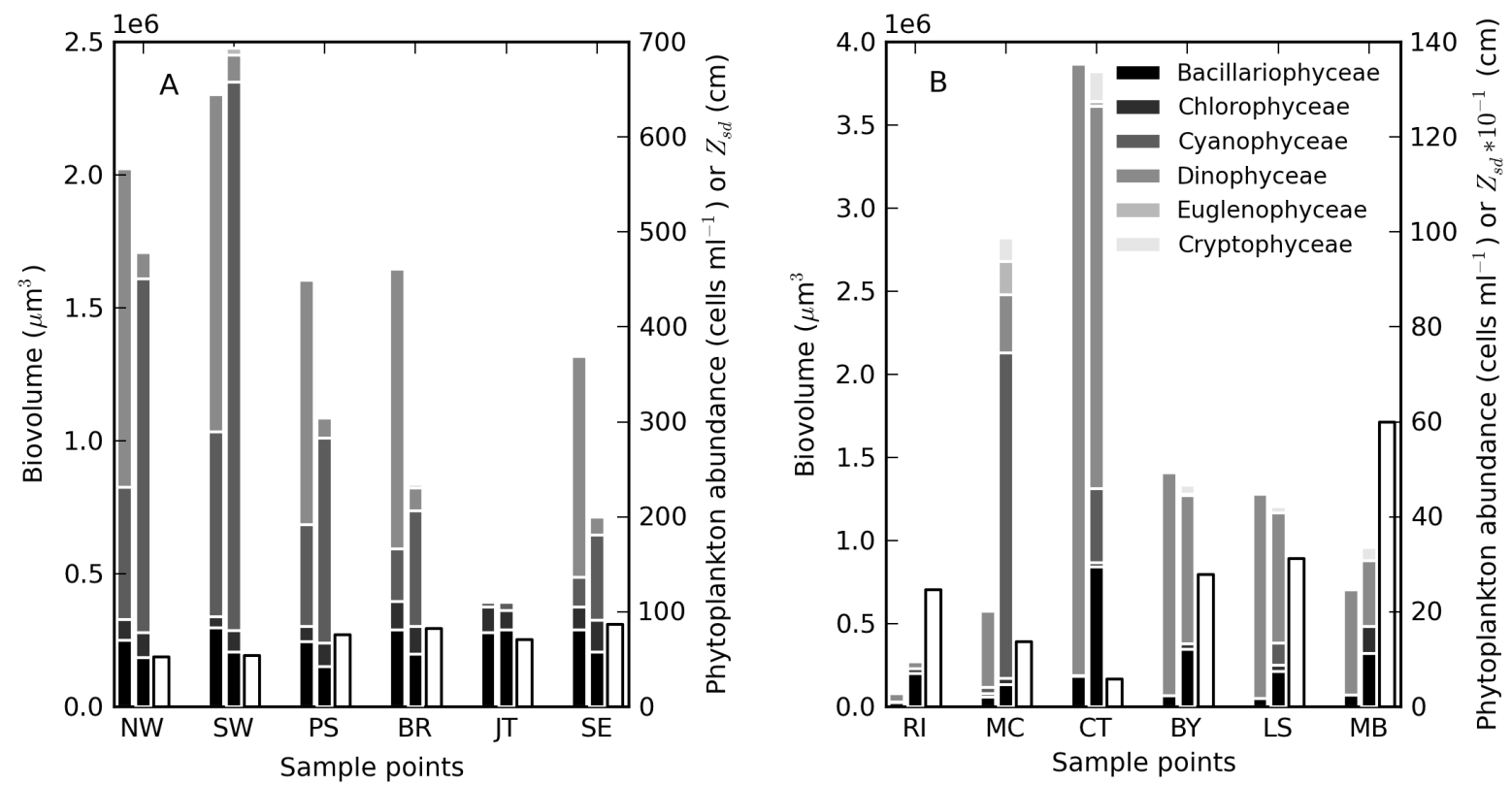
A general pattern of increasing turbidity and phytoplankton biomass can be observed from the eastern basin towards the western basin, near the inflow of the Sonderend River (Figure 3A). The eastern basin is mesotrophic (chl- $a \approx 10 \mathrm{mg} \cdot \mathrm{m}^{-3}$ ). At the bridge (point $\mathrm{BR}$ ), the water is typically meso-eutrophic with mixed blooms of cyanobacteria, chlorophytes and diatoms. The western basin (points SW and $\mathrm{NW}$ ) is hyper/eutrophic with decreased water clarity $\left(\right.$ mean $\left.z_{s d}=50 \mathrm{~cm}\right)$ associated with the presence of a mixed bloom of Anabaena ucrainica and Sphaerodinium fimbriatum (Figure 3A). These species are co-dominant in terms of biovolume. During strong wind, sampling was carried out at point PS (pump station) near the water abstraction pump station.

\subsection{Absorption by Gelbstoff}

From an optical perspective, phytoplankton biomass and suspended particles appear to have greater influence on water clarity than dissolved organic matter, based on the observed water color. The measured $a_{g}$ curves are relatively consistent with an exponential function (straight lines in Figure 4A). $a_{g}(442)$ varies in a relatively narrow range from 0.63 to $4.13 \mathrm{~m}^{-1}$ (Table 1). Despite its large trophic gradient, Loskop has the most narrow range, from 0.75 to $1.87 \mathrm{~m}^{-1}$. Therefore, $a_{g}$ is essentially independent of trophic status. The widest range of values is found in Hartbeespoort $\left(0.63\right.$ to $\left.4.13 \mathrm{~m}^{-1}\right)$, likely associated with extremely variable cyanobacterial biomass. Theewaterskloof has the highest average value of $1.9 \mathrm{~m}^{-1}$, which is consistent with the geological and floral environment associated with brackish Cape waters. An inverse relationship is generally present between $S_{g}$ and $a_{g}(442)$; however, greater variability is associated with smaller values of $a_{g}(442)$ (see [3] Figure 4B). $S_{g}$ ranges between 0.012 and $0.022 \mathrm{~nm}^{-1}$, within the range reported in coastal [3] and inland waters [49]. Mean values determined for Loskop and Hartbeespoort are $0.017 \mathrm{~nm}^{-1}$, while that for Theewaterskloof is $0.014 \mathrm{~nm}^{-1}$.

Figure 4. (A) $a_{g}$ curves on the log scale axis; (B) $a_{g}(442)$ versus the exponential slope coefficient, $S_{g}$. The legend colors are the same in A and B.
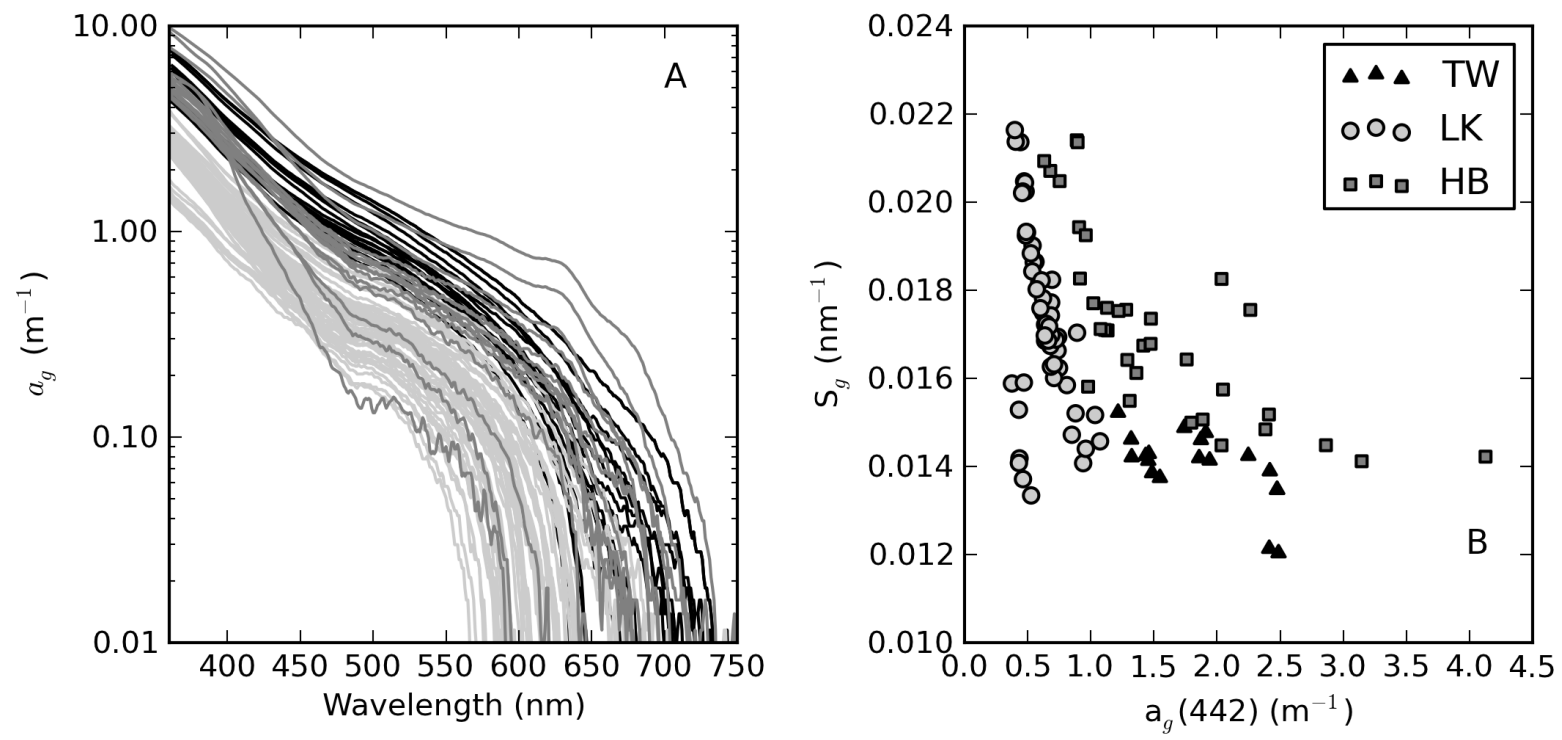


\subsection{Absorption by Seston}

Figure 5 shows the measured $a_{p}$ spectra, which vary over more than four orders of magnitude. Extremely high $a_{p}$ values were measured in surface scum in Hartbeespoort (Table 2, Figure 5A). These spectra have shapes that indicate that the contribution of phytoplankton to $a_{p}$ is overwhelming. The spectra for Loskop are divided into two groups to facilitate comparison-the first is from the high biomass $C$. hirundinella bloom at sampling point CT (Figure 5B) and the second is from other sample points (Figure 5C). The spectra from point CT are strongly dominated by phytoplankton absorption, while the remainder have more exponential shapes, evidence of relatively larger tripton influence. $a_{p}$ spectra measured in Theewaterskloof (Figure 5C) appear to be influenced by significant contributions of both tripton and phytoplankton, with strong exponential shapes at wavelengths $<500 \mathrm{~nm}$.

$a_{p}(442)$ is most variable in Hartbeespoort and Loskop $\left(0.16-456.24 \mathrm{~m}^{-1}\right)$ and was least variable in Theewaterskloof $\left(1.13-3.65 \mathrm{~m}^{-1}\right) . \quad a_{p}(442)$ is highly covariant with seston and chl- $a$ concentrations (Figure 6). A null intercept linear function $(y=a x)$ was used to fit the data. The relationship $a_{p}(442)=0.23 \times$ seston was determined for Loskop $\left(\mathrm{r}^{2}=0.91, \mathrm{SE}\right.$ (standard error) $\left.=1.03, \mathrm{~N}=56\right)$, similar to that determined for Theewaterskloof, $a_{p}(442)=0.12 \times$ seston $\left(\mathrm{r}^{2}=0.97, \mathrm{SE}=0.38\right.$, $\mathrm{N}=19)$. For combined Theewaterskloof and Loskop data, the relationship is $a_{p}(442)=0.19 \times$ seston $\left(\mathrm{r}^{2}=0.85, \mathrm{SE}=1.22, \mathrm{~N}=75\right)$. The variation in the regression coefficient, $a$, demonstrates the variability in the underlying IOPs. $a_{p}(442)$ was better described by chl- $a$ in Hartbeespoort according to $a_{p}(442)=0.026 \times$ chl $-a\left(\mathrm{r}^{2}=0.82, \mathrm{SE}=67.9, \mathrm{~N}=19\right)$. The combined dataset was described by $a_{p}(442)=0.15 \times$ seston $\left(\mathrm{r}^{2}=0.68, \mathrm{SE}=40.25, \mathrm{~N}=91\right)$, and $a_{p}(442)=0.026 \times$ chl $-a\left(\mathrm{r}^{2}=0.82\right.$, $\mathrm{SE}=29.9, \mathrm{~N}=94)$. The significance of the regressions is affected by the very high seston and chl- $a$ concentrations in Hartbeespoort.

Figure 5. $a_{p}$ spectra measured in (A) Hartbeespoort (gray lines scaled by 0.1 to facilitate comparison), (B) Loskop for $a_{p}(442)>2 \mathrm{~m}^{-1}$ and (C) Theewaterskloof (black lines) and Loskop for $a_{p}(442)<2 \mathrm{~m}^{-1}$ (gray lines).
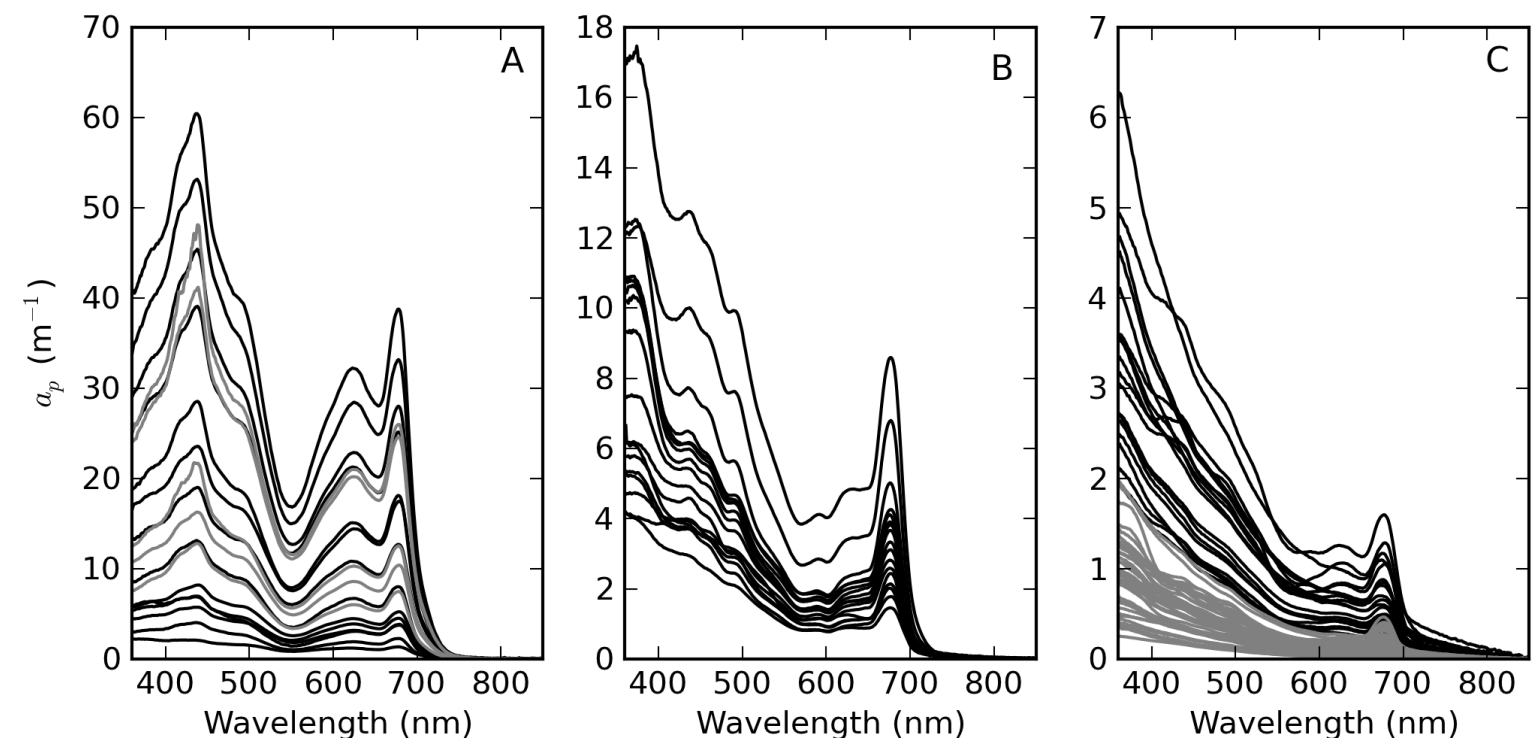
Figure 6. $a_{p}(442)$ versus (A) seston showing linear fits for Loskop (- -), Theewaterskloof $(-\cdot)$ and combined data (-), and (B) chl- $a$ showing the linear fit for Hartbeespoort (-). Note the $\log$ scales.
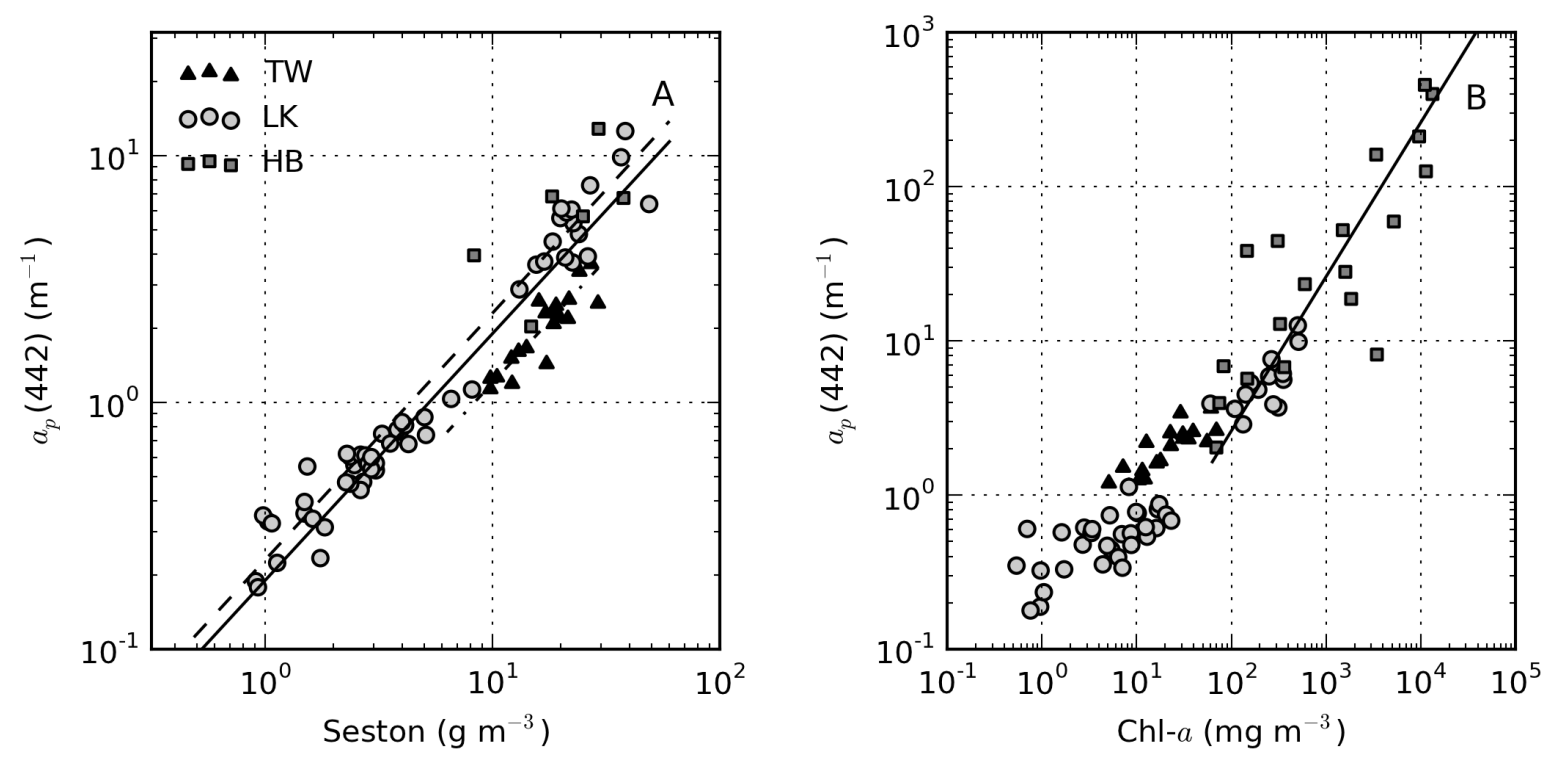

\subsection{Absorption by Tripton}

Figure 7 shows $a_{t r}$ spectra from a single sample with a mixed cyanophyte/diatom/chlorophyte assemblage from Theewaterskloof determined by both hot methanol extraction and $\mathrm{NaClO}$ bleaching methods. The differences in magnitude of $a_{p}$ in Figure 7A are due only to the expected differences between duplicate samples. However, after normalizing at $410 \mathrm{~nm}$ (Figure 7B), appreciable spectral differences are present, as well as in the corresponding $a_{p h}$ spectra. Although no apparent residual PC absorption peak at $620 \mathrm{~nm}$ is visible in the spectra, the methanol determined $a_{t r}: a_{p}$ ratio spectrum reveals that residual phycobilipigments are present in the region 500-650 nm, when compared to that determined by $\mathrm{NaClO}$ (Figure 7C). The difference between the $a_{t r}: a_{p}$ ratio spectra of the two methods shows that the hot methanol method leads to a 15\%-20\% underestimate of $a_{\phi}$ (or overestimate of $a_{t r}$ ) in the region between 500 and $650 \mathrm{~nm}$ (Figure 7D). The shoulders near 420 and $650 \mathrm{~nm}$ are likely associated with residual chl- $b$ pigment from Chlorophyceae, which also results in a $\pm 4 \%$ difference in the $675 \mathrm{~nm}$ chl- $a$ absorption peak. Some evidence of bleaching of organic detritus by $\mathrm{NaClO}$ is visible from 700 to $750 \mathrm{~nm}$ (although not $<440 \mathrm{~nm}$ ), with both methods being roughly equivalent from $800 \mathrm{~nm}$ onwards. Therefore, in this example, the hot methanol technique resulted in residual phycobili and chlorophyte pigments in $a_{t r}$, while there was bleaching of organic detritus by $\mathrm{NaClO}$ in the near infra-red (NIR) region.

Some selected examples further illustrate these and other unusual features present in the measured $a_{t r}$ spectra (Figure 8). In Theewaterskloof, a strong absorption feature near 450-550 nm, which is likely to be associated with iron oxides, was visible [52]; some residual chl- $a$ absorption is also apparent (Figure 8A). In a few examples, residual phycobilipigment features were clearly visible (Figure 8B). To overcome this methodological error in the Theewaterskloof data, $S_{t r}$ was calculated using an exponential function fitted between 360 and $500 \mathrm{~nm}$. Another unusual feature was a flattening $<440 \mathrm{~nm}$ for $a_{t r}$ measured at point MB in Loskop (Figure 8C), the origin of which is unknown 
(see similar feature in Baltic spectra in [3]). For these data, an exponential function fitted between 440-600 nm was used to calculate $S_{t r}$. Iron oxide features (less obvious) were also present for some spectra in Loskop (Figure 8D). In Hartbeespoort, unusually steep slopes affecting wavelengths $<450 \mathrm{~nm}$ were clearly visible (Figure 8E). Heterotrophic bacteria are known to be present in Hartbeespoort and other hypertrophic lakes in high abundance [53]. Therefore, the effect is likely to be caused by yellow cytochrome byproducts from $\mathrm{NaClO}$ bleaching, which are deposited on the filters [46]. All but two of the measured $a_{t r}$ spectra in Hartbeespoort were contaminated by this effect. Therefore, $S_{t r}$ was only computed for two uncontaminated spectra in Hartbeespoort, which also displayed some iron oxide effects (Figure 8F). Corrected $a_{t r}$ spectra were computed by extrapolating the value at $460 \mathrm{~nm}$ using an exponential function with a slope coefficient $=0.009 \mathrm{~nm}^{-1}$. The extremely high biomass and the presence of heterotrophic bacteria in M. aeruginosa blooms in Hartbeespoort meant that determination of $a_{t r}$ was challenging. Obvious residual phycobilipigment features were also sometimes present, resulting from inefficient $\mathrm{NaClO}$ bleaching. Therefore, determination of $a_{t r}$ in hypertrophic waters or surface scum is perhaps better performed using a numerical technique (e.g., [44]). However, the contribution of tripton to $a_{p}$ was very small (see below).

Figure 7. Comparison between $\mathrm{NaClO}$ and hot methanol methods for determining $a_{t r}$. (A) $a_{p}$ and $a_{t r}$ determined using both methods for a single sample from Theewaterskloof; (B) $a_{p}$ and $a_{t r}$ normalized at $410 \mathrm{~nm}$; (C) $a_{t r}: a_{p}$ ratio in percent; (D) percent difference between hot methanol and $\mathrm{NaClO}$ determined $a_{t r}: a_{p}$ ratios shown in $(\mathrm{C})$.
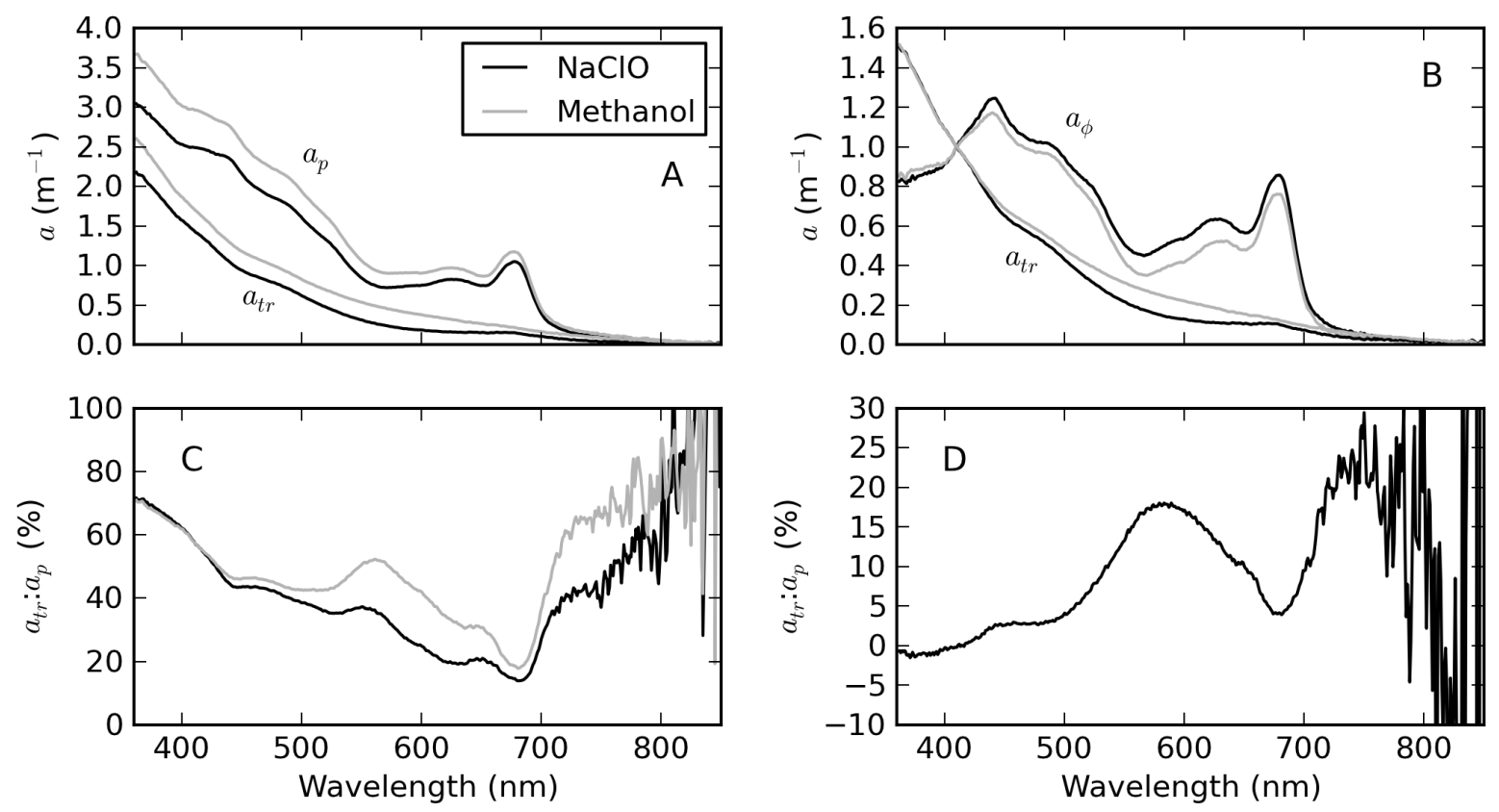
Figure 8. Selected $a_{t r}$ examples showing measured data (solid line) and the corresponding exponential fit (dashed line). The sample point ID is shown in brackets.


The complete set of measured $a_{t r}$ curves are shown in Figure 9 alongside histograms for $S_{t r}$ and $a_{t r}(442)$. In general, an exponential function closely fitted the data, evident by the straight lines on the log-scale plot (Figure 9A). Of the three reservoirs, Theewaterskloof has the highest mean $a_{t r}(442)$ value $\left(=1.18 \mathrm{~m}^{-1}\right)$, nearly twice that of Loskop and Hartbeespoort (see Table 1$) . a_{t r}(442)$ also has the highest range $\left(=1.75 \mathrm{~m}^{-1}\right)$ in Theewaterskloof. This might be related to the high mineralic component of seston and the windy climatology of the reservoir. The range of $a_{t r}(442)$ values for Hartbeespoort and Loskop are very similar (mean $=0.51$ and $0.53 \mathrm{~m}^{-1}$, respectively), despite the extremely variable trophic conditions. This is because the variability in $a_{t r}(442)$ is only weakly influenced by phytoplankton biomass (see below). The distributions of $a_{t r}(442)$ for Hartbeespoort and Loskop are skewed towards smaller values and may generally be described by an inverse-Gaussian function (Figure 9C). Therefore, there is an increased probability of encountering $a_{t r}(442)$ values $<0.5 \mathrm{~m}^{-1}$ in these systems, while 
it is also unlikely to encounter values $>2 \mathrm{~m}^{-1}$. The Theewaterskloof data conforms more closely to a normal distribution with an increased likelihood of encountering $a_{t r}(442)$ values near $1.0 \mathrm{~m}^{-1}$. The values determined for $S_{t r}$ vary in a narrow range between 0.008 and $0.013 \mathrm{~nm}^{-1}$, with a mean value of $0.010 \mathrm{~nm}^{-1}$ for all reservoirs (Table 1, Figure 9B). These are typical of those measured in other inland and coastal waters (e.g., [3,9,37]). The distribution of $S_{t r}$ generally follows the shape of a normal distribution; therefore, the highest probability value is near $0.010 \mathrm{~nm}^{-1}$.

Figure 9. (A) $a_{t r}$ spectra for all reservoirs using the log-scale y-axis; (B) histogram of the exponential slope coefficient, $S_{t r}$, for each reservoir showing normal distributions with integrals equal to the data; $(\mathbf{C})$ histogram of $a_{t r}(442)$ for each reservoir showing fitted inverse-Gaussian and normal distributions with integrals equal to the data. The legend is the same in all panels.
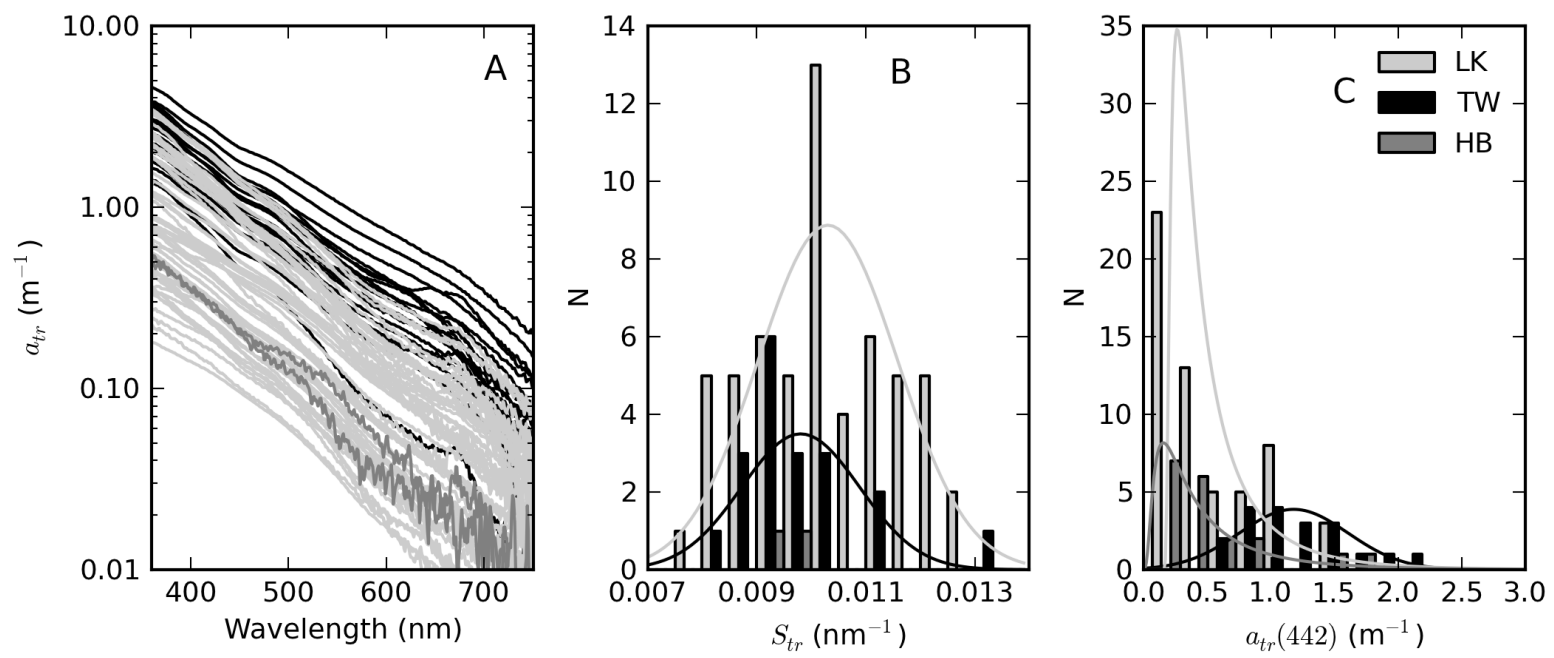

Figure 10. $a_{t r}(442)$ versus (A) seston, showing the fit for combined Theewaterskloof and Loskop data (-) and that from Binding et al. [9] (- -); (B) chl-a; and (C) minerals showing the fit for combined Theewaterskloof and Loskop data (-). The legend is identical in all plots. Note log-scales.
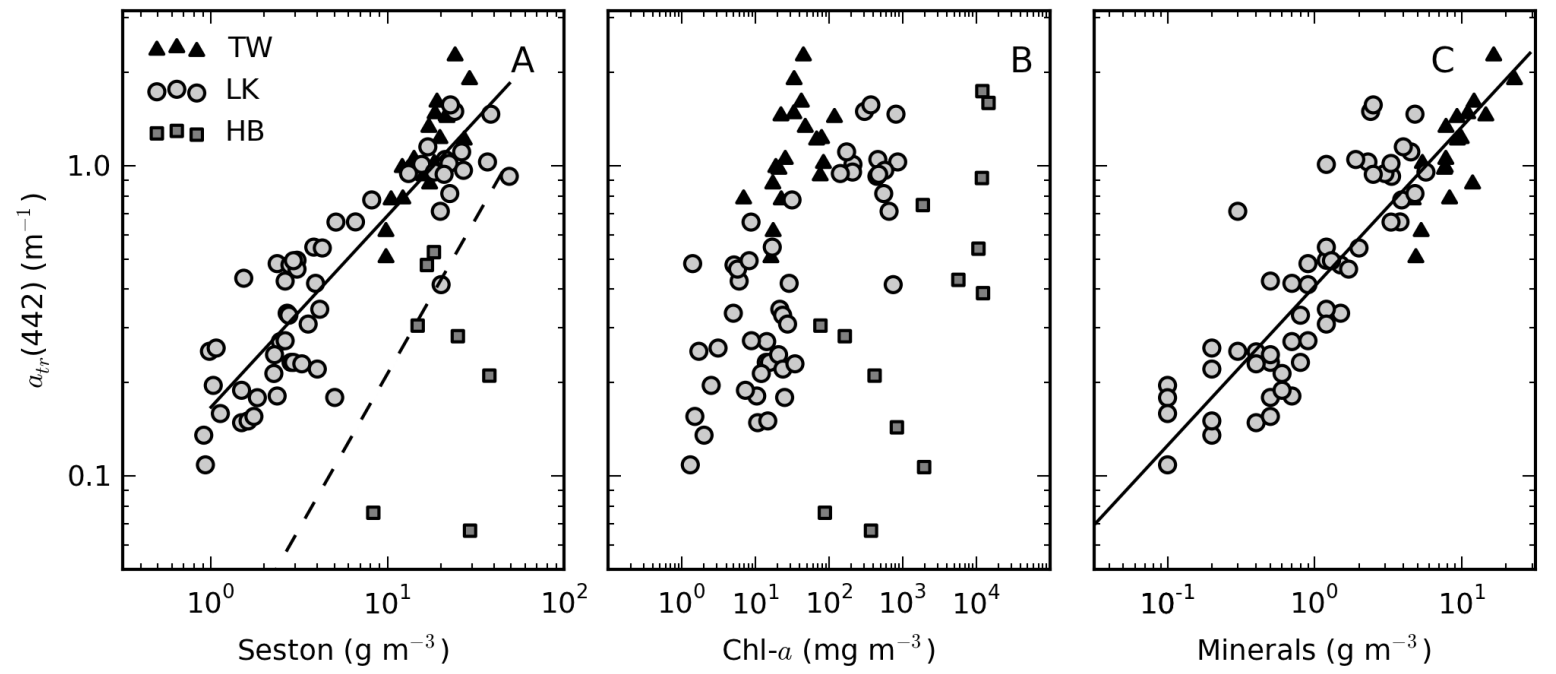
$a_{t r}(442)$ is significantly positively correlated with seston for Theewaterskloof and Loskop; the relationship is best described by a power-law fit as $a_{t r}(442)=0.17 \times \operatorname{seston}^{0.62}\left(r^{2}=0.81, \mathrm{~N}=74\right)$ (Figure 10A). A null-point linear fit, such as those determined by Binding et al. [9] in lake Erie (drawn in Figure 10A) and Babin et al. [3] in European coastal waters, poorly describes the lower range of the data. In Hartbeespoort, the relationship is poor $\left(r^{2}=0.32, \mathrm{~N}=16\right)$. This could result from errors in the corrected $a_{t r}(442)$ values or methodological errors associated with $a_{t r}$ determination in surface scum conditions. However, it may also be more simply explained by tripton making up an insignificant proportion of the dry weight, the majority of which is living cells. There is considerable scatter between $a_{t r}(442)$ and TChl, which varies over six orders of magnitude (Figure 10B). Weak positive correlations are apparent within the reservoirs, indicating that trophic status weakly covaries with $a_{t r}(442)$ within the systems. The significant offset for Hartbeespoort data indicates that in surface scum conditions, the tripton:phytoplankton ratio is significantly lowered. In contrast, the grouping of Theewaterskloof data towards the left of the plot is indicative of an enlarged tripton:phytoplankton ratio, in this case, presumably resulting from a higher mineralic component. Mineral (ash) dry weight and $a_{t r}(442)$ are highly correlated with a fit for combined Loskop and Theewaterskloof data of $a_{t r}(442)=0.0 .41 \times$ minerals $^{0.51} r^{2}=0.77, \mathrm{~N}=70$ (Figure 10C). The clustering of the Theewaterskloof data towards the top right of the plot is evidence of the high mineral content of seston (mean mineral contribution to seston $=57 \%$ ). This may be a result of the high silica content of abundant diatom species.

Figure 11. Scatter plots of $a_{t r}$ (442) versus $a_{p}(442)$ for (A) Theewaterskloof and Loskop, with $a_{p}<2$ showing the linear fit (-), and (B) Hartbeespoort and Loskop with $a_{p}>2$. Color bars display the ratio of $a_{t r}: a_{p}$. (C) TChl versus the ratio $a_{t r}: a_{p}$, showing the power-law fit for Loskop. Note the log-scaled axes in $(\mathrm{B}, \mathrm{C})$.
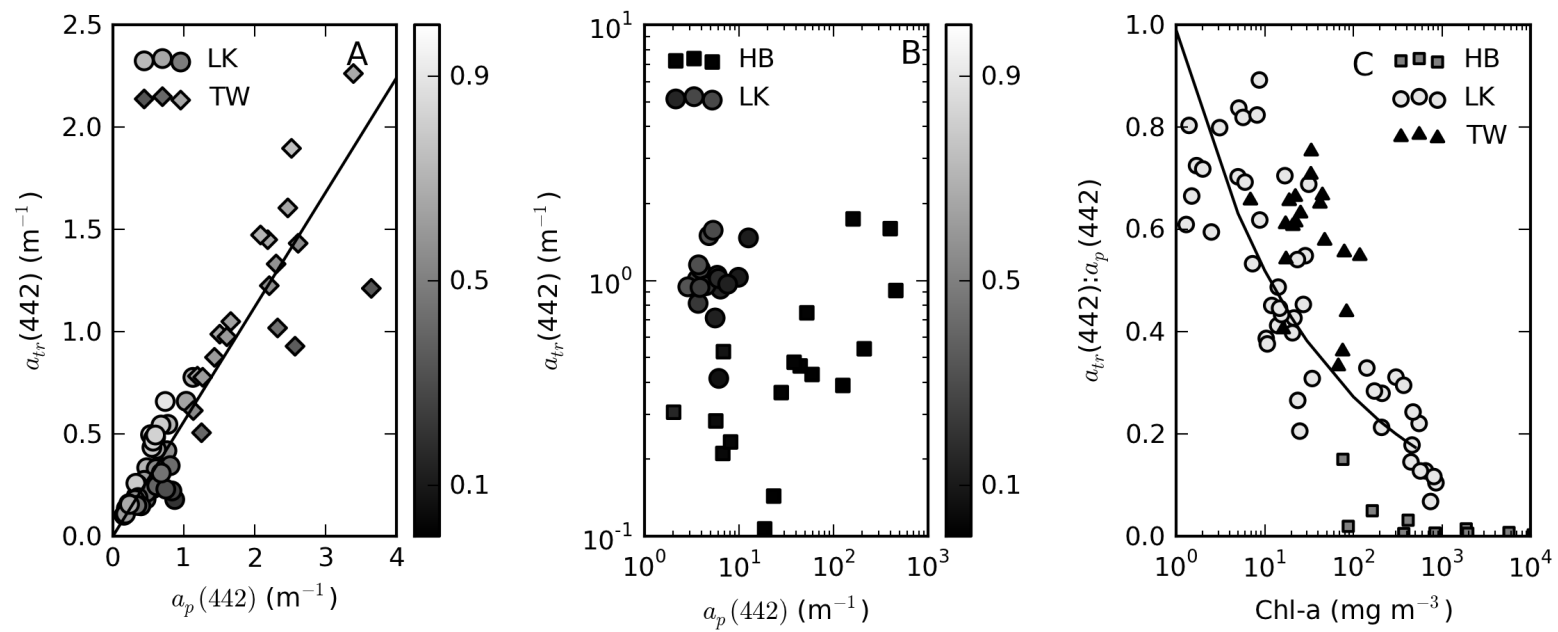

The variability in the contribution of tripton to $a_{p}$ between and within the reservoirs warrants closer investigation. For samples with $a_{p}(442)<2$, a positive linear relationship between $a_{t r}(442)$ and $a_{p}(442)$ exists: $a_{t r}(442)=0.56 \times a_{p}(442), r^{2}=0.94, \mathrm{SE}=0.2, \mathrm{~N}=58$ (Figure 11A). Mean $a_{t r}(442): a_{p}(442)$ ratios for these data are 0.65 for Theewaterskloof (range $=0.35-0.75$ ) and 0.7 (range $=0.4-0.9$ ) for Loskop. Tripton, therefore, has a large contribution to particulate absorption for these data. For high biomass Loskop and Hartbeespoort waters, the relationship between $a_{t r}$ and $a_{p}$ breaks down 
(Figure 11B). In these waters, $a_{t r}$ is an insignificant contributor to $a_{p}$, with $a_{t r}(442): a_{p}(442)$ ratios of $0.1-0.35$ in Loskop and $<0.15$ in Hartbeespoort. When investigating the change in the $a_{t r}(442): a_{p}(442)$ ratio relative to phytoplankton biomass (TChl), we find a general inverse correlation, which is specific to each lake (Figure 11C). In Loskop, the relationship is described by $a_{t r}(442): a_{p}(442)=0.99 \times \mathrm{TChl}^{-0.28}$ $\left(r^{2}=0.76, \mathrm{~N}=47\right)$, while in Hartbeespoort, it is $a_{t r}(442): a_{p}(442)=0.37 \times \mathrm{TChl}^{-0.50}\left(r^{2}=0.62\right.$, $\mathrm{N}=14)$. In Theewaterskloof, the relationship was much weaker $\left(r^{2}=0.2\right.$ for a linear fit $)$, signifying that phytoplankton biomass does not dictate the contribution by tripton to particulate matter. Evidently, tripton typically contributes more towards $a_{p}(442)$ as phytoplankton biomass decreases. Therefore, phytoplankton biomass exerts a controlling influence on the contribution that tripton makes to particulate absorption (although less so for Theewaterskloof). The converse effect is visible in a weak positive correlation between minerals and the $a_{t r}(442): a_{p}(442)$ ratio (not shown). There is no apparent relationship between the ratio and seston concentration.

\subsection{Mass-Specific Tripton Absorption}

The chl- $a$ content of seston (chl- $a$ :seston ratio) might be used to test for steady state conditions [36]. Figure 12A shows the mean chl- $a$ :seston ratio determined for different sample points in Loskop and for Theewaterskloof and Hartbeespoort as a whole. Non-steady-state conditions were indicated by widely variable ratios at point CT in Loskop $\left(6-18 \mathrm{mg} \cdot \mathrm{g}^{-1}\right)$ and in Hartbeespoort $\left(4-11 \mathrm{mg} \cdot \mathrm{g}^{-1}\right)$. Variability elsewhere was relatively small. Therefore, non-steady-state conditions are associated with the high biomass blooms in Loskop and Hartbeespoort. $R_{p d}$ is, therefore, expected to be larger than 0.3 in these blooms, but should be near 0.3 elsewhere, regardless of the trophic state.

The $R_{p d}$ values calculated using $\beta$ ranging between $0.01-0.1 \mathrm{~g} \cdot \mathrm{mg}^{-1}$ and averaged by the sample point/reservoir are shown in Figure 12B. For steady-state Loskop sample points, BY (buoy), LS and MB, values of $\beta$ corresponding to $R_{p d} \approx 0.3$ are approximately $0.04,0.055$ and $>0.1 \mathrm{~g} \cdot \mathrm{mg}^{-1}$, respectively. By choosing a single value of $\beta=0.04 \mathrm{~g} \cdot \mathrm{mg}^{-1}$ for Loskop, the corresponding $R_{p d}$ values become $0.29,0.20$ and 0.04. This is in the acceptable range of values encountered in steady-state conditions considering that chl- $a$ at point $\mathrm{MB}$ was very small, $>1 \mathrm{mg} \cdot \mathrm{m}^{-3}$. The value determined for $\beta$ is lower than the mean value for $C$. hirundinella $\left(=0.079 \mathrm{~g} \cdot \mathrm{mg}^{-1}\right.$ [39]), but is within the lower range determined for natural populations of flagellates $\left(=0.037-0.714 \mathrm{~g} \cdot \mathrm{mg}^{-1}[38]\right)$. Assuming the same value for $\beta$ can be used for the bloom at point CT, the corresponding $R_{p d}$ is 1.3 . Such a high value might be acceptable, since negative $R_{p d}$ values are observed for $\beta$ values $>0.05 \mathrm{~g} \cdot \mathrm{mg}^{-1}$ at point CT. This is a result of phytoplankton dry mass calculated using $\beta$ exceeding seston dry weight.

Because of the difficulty in measuring parameters in surface scum conditions, only samples with chl- $a<500 \mathrm{mg} \cdot \mathrm{m}^{-3}$ were used in the calculations. The value for $\beta$ determined in Hartbeespoort is approximately $0.03 \mathrm{~g} \cdot \mathrm{mg}^{-1}$ (Figure 12B), just under the range of $0.033-0.769 \mathrm{~g} \cdot \mathrm{mg}^{-1}$ determined by Desortová [38] for blue-green assemblages. However, a $R_{p d}$ value of 0.3 is likely too low for the non-steady-state bloom conditions. The average literature value of $\beta$ for M. aeruginosa $=0.09 \mathrm{~g} \cdot \mathrm{mg}^{-1}[37,39]$ gives a $R_{p d}=1.83$ (one negative value was removed from the calculations, $\mathrm{N}=17$ ). This $R_{p d}$ is similar to that obtained at point CT in Loskop. Theoretically, however, $\beta$ could lie anywhere between 0.03 and $0.09 \mathrm{~g} \cdot \mathrm{mg}^{-1}$ in Hartbeespoort. In Theewaterskloof, a $\beta$ value of 
$0.09 \mathrm{~g} \cdot \mathrm{mg}^{-1}$ was determined. This is close to literature values for Anabaena $=0.063 \mathrm{~g} \cdot \mathrm{mg}^{-1}$ and lower than those for diatoms Asterionella and Aulacoseira $\left(\beta=0.18\right.$ and $\left.0.12 \mathrm{~g} \cdot \mathrm{mg}^{-1}\right)$ [39], both of which are present in Theewaterskloof. In summary, $\beta$ values for Loskop, Hartbeespoort and Theewaterskloof were finally chosen as $0.04,0.09$ and $0.09 \mathrm{~g} \cdot \mathrm{mg}^{-1}$, respectively.

Figure 12. (A) Mean chl- $a$ :seston values and (B) mean $R_{p d}$ values calculated for values of $\beta$ between 0.01 and $0.10 \mathrm{~g} \cdot \mathrm{mg}^{-1}$ for sample points in Loskop, Theewaterskloof and Hartbeespoort; (C) histograms of $a_{t r}^{*}(442)$ for each reservoir; (D) the mean $a_{t r}^{*}$ spectrum showing standard deviations $(. \cdot)$ for each reservoir.
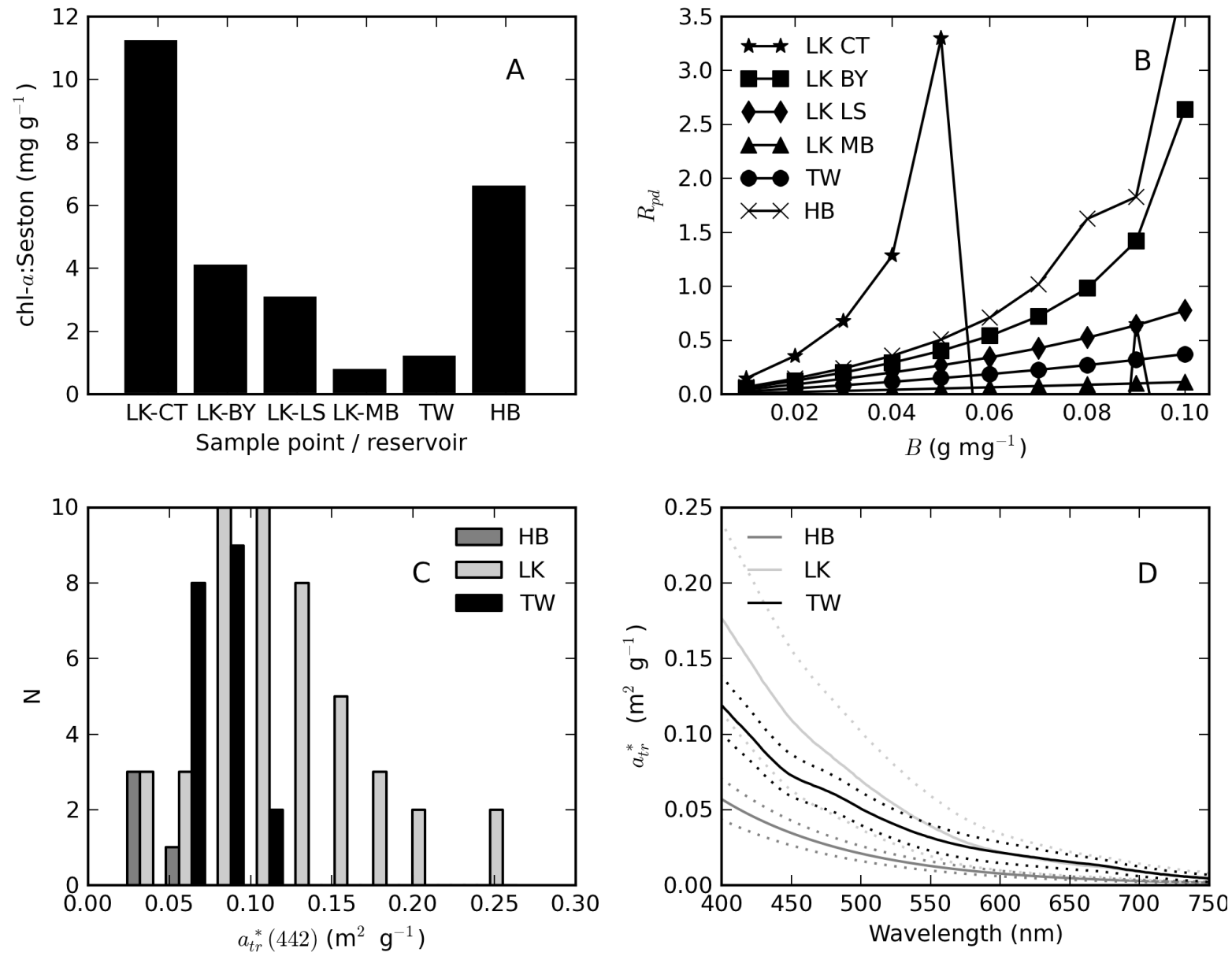

The $a_{t r}^{*}(442)$ values determined using the aforementioned $\beta$ values are shown in Figure 12C, and the mean $a_{t r}^{*}$ spectrum for each reservoir in Figure 12D. $a_{t r}^{*}(442)$ ranges from 0.025 to $0.263 \mathrm{~m}^{2} \cdot \mathrm{g}^{-1}$ in Loskop, 0.054 to $0.105 \mathrm{~m}^{2} \cdot \mathrm{g}^{-1}$ in Theewaterskloof and from 0.024 to $0.048 \mathrm{~m}^{2} \cdot \mathrm{g}^{-1}$ in Hartbeespoort. The mean values are $0.119,0.078$ and $0.037 \mathrm{~m}^{2} \cdot \mathrm{g}^{-1}$, respectively. These values compare favorably with those reported in other fresh inland waters (e.g., [6,33,37]). In particular, values of $a_{t r}^{*}(550)$ for various lakes in Queensland Australia varied between 0.014 and $0.145 \mathrm{~m}^{2} \cdot \mathrm{g}^{-1}$ [6]. The mean spectrum for Theewaterskloof is evidently mineral-rich and affected by iron oxide absorption effects near $500 \mathrm{~nm}$. The specific absorption coefficients of terrigenous mineral-rich particulate matter vary over a wide range from $<0.1$ to $1 \mathrm{~m}^{2} \cdot \mathrm{g}^{-1}$ (e.g., [54,55]). Therefore, the values determined here appear to be consistent within the variability present in the literature. A brief investigation of the sensitivity of $a_{t r}^{*}(442)$ to the 
value of $\beta$ shows that in Hartbeespoort, mean $a_{t r}^{*}(442)$ values produced by $\beta$ of 0.03 and $0.09 \mathrm{~g} \cdot \mathrm{mg}^{-1}$ are 0.0145 and $0.0374 \mathrm{~m}^{2} \cdot \mathrm{g}^{-1}$, respectively. Therefore, the value of $\beta$ has an appreciable influence on $a_{t r}^{*}(442)$ and should, therefore, be chosen with care, for example, using the method presented here.

\subsection{Absorption by Phytoplankton}

$a_{\phi}$ for Theewaterskloof was calculated without correcting the $a_{t r}$ spectra for residual phycobilipigment, because of the strong iron oxide absorption feature. Therefore, $a_{\phi}$ may be underestimated by a maximum of $15 \%$ in the region $550-650 \mathrm{~nm}$ for these data. In the case of Hartbeespoort, an exponential function with slope $S_{t r}=0.010$ (the mean value determined for uncontaminated spectra) was used with the value of $a_{t r}$ determined at $460 \mathrm{~nm}$ to calculate $a_{\phi}$. This was because $a_{t r}$ was contaminated by $\mathrm{NaClO}$ bleaching of heterotrophic bacteria. As the contribution to $a_{p}$ by tripton was so small relative to phytoplankton (see Figure 11), the effect of this correction on $a_{\phi}$ is insignificant.

Figure 13. Spectral $a_{\phi}$ for (A) Hartbeespoort (gray lines scaled by 0.1); (B) Loskop for $a_{p}(442)>1$; (C) Theewaterskloof; and (D) Loskop for $a_{p}(442)<1$.
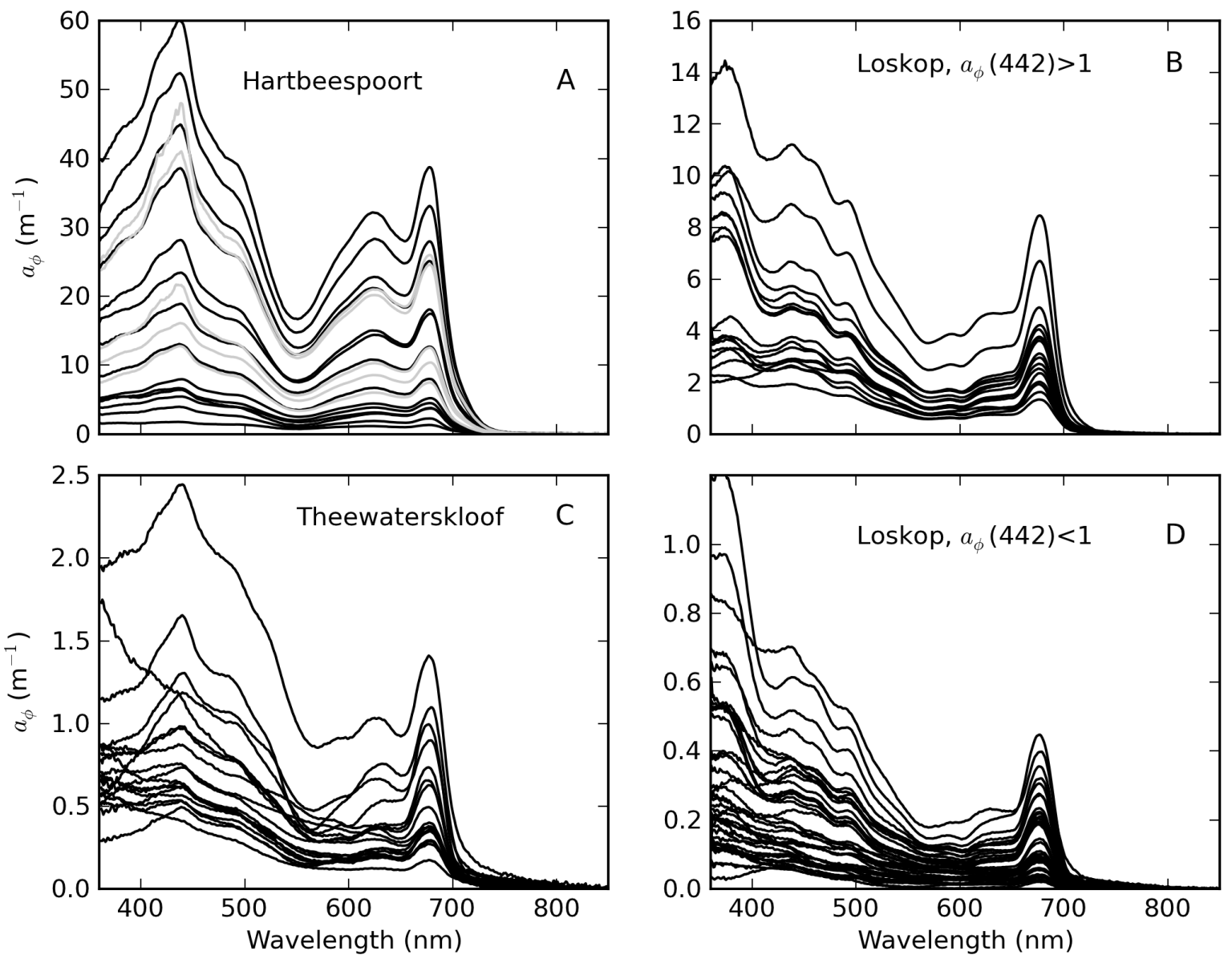

The diversity of trophic states and phytoplankton assemblages between and within the reservoirs was evident in $a_{\phi}$ spectra that vary widely in shape and magnitude (Figure 13). Extremely high $a_{\phi}$ values $>400 \mathrm{~m}^{-1}$ were measured in M. aeruginosa surface scums in Hartbeespoort (Figure 13A). 
The spectral shapes have typical chl-a absorption peaks along with strong phycobilipigment features between 550-650 nm (phycocyanin and phycoerethrin) and shoulders associated with the carotenoids myxoxanthophyll, zeaxanthin and echinenone (400-500 nm) [56,57]. The spectra from Loskop are much smaller in magnitude, with significantly different pigmentation features associated mainly with C. hirundinella. These have absorption shoulders in the region 400-500 $\mathrm{nm}$ from chlorophylls c1 + c2 $(440 \mathrm{~nm})$, the carotenoids, peridinin $(460 \mathrm{~nm})$ and, possibly, fucoxanthin $(440-460 \mathrm{~nm})$, and xanthophylls (diadinoxanthin, diatoxanthin) [57]. The presence of UV photoprotective mycosporine-like amino acids (MAAs) typical of dinoflagellates is strikingly evident $<400 \mathrm{~nm}$ [58]. $a_{\phi}$ spectra from Theewaterskloof have a mix of dinoflagellate and cyanobacterial pigment absorption features, both species being co-dominant. These and other features are described further in Figure 14.

Figure 14. Selected examples of $a_{\phi}^{*}$ for (A) oligotrophic, (B) mesotrophic and (C) hypertrophic waters. Spectra are labeled with dominant phytoplankton type(s), reservoir and TChl concentration. (D) The mean and standard deviation (..) of $a_{\phi}^{*}$ for each reservoir. Loskop data were divided into sample point $\mathrm{CT}$ and all other points.
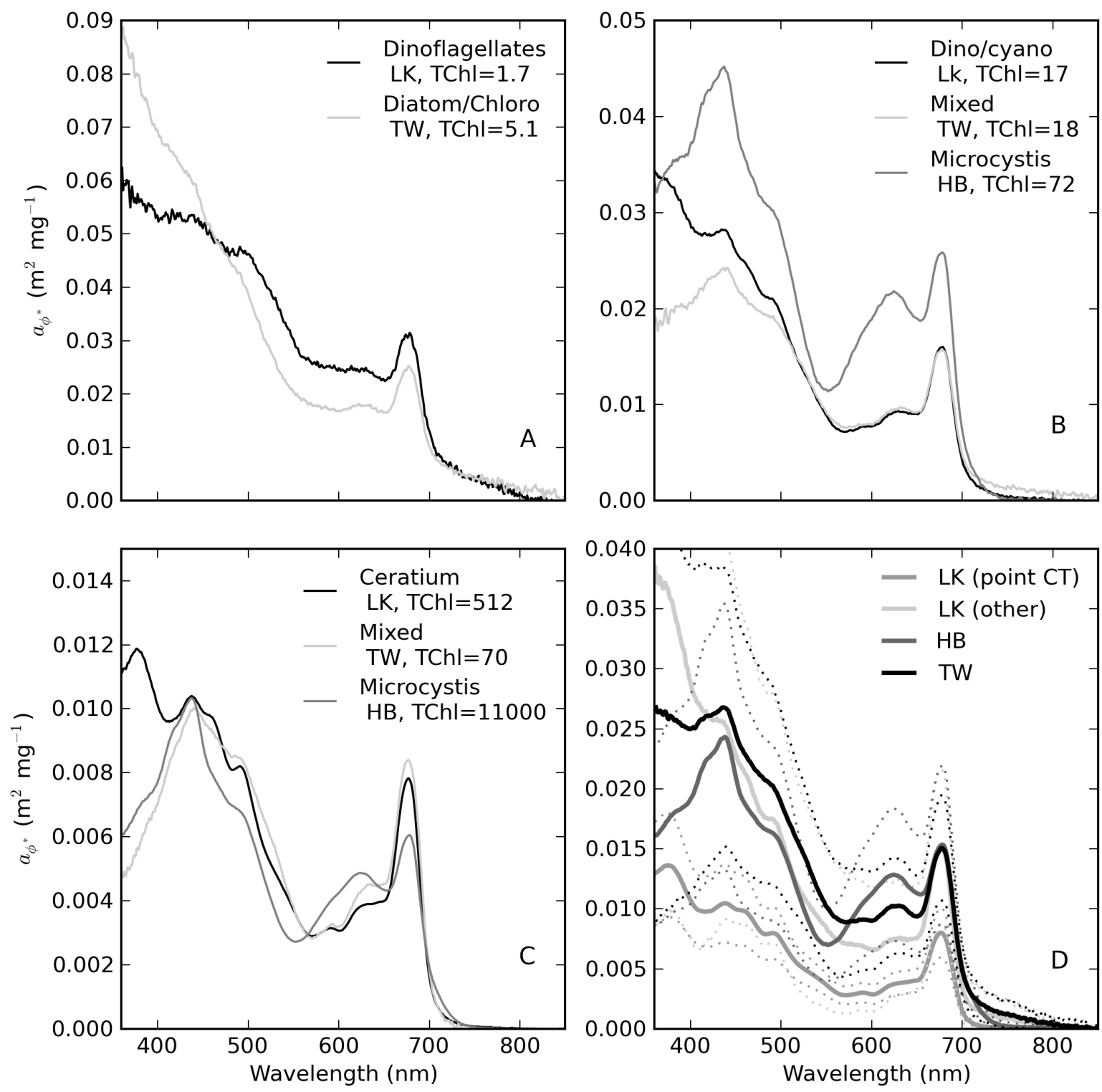
Five of the $a_{\phi}$ spectra for Loskop determined using $\mathrm{NaClO}$ bleaching had shapes that increased exponentially towards the blue. These spectra were associated with low chl- $a$ values $\left(<1 \mathrm{mg} \cdot \mathrm{m}^{-3}\right)$ and relatively high gelbstoff concentrations $\left(a_{g}(440)=0.94-1.5 \mathrm{~m}^{-1}\right)$. It is possible that this affect may be caused by $\mathrm{NaClO}$ bleaching of dissolved organic matter (DOM) in the presence of relatively high gelbstoff absorption [9]. However, because of the presence of a strong signal from MAAs $<400 \mathrm{~nm}$, it is difficult to ascertain whether bleaching did in fact occur (see Figure 7). For example, a similar effect was also visible in two spectra from Theewaterskloof. Since these were determined using boiling methanol, the effect cannot be caused by $\mathrm{NaClO}$ bleaching and is probably better attributed to accessory pigments (MAAs), methodological errors or an unknown source. There was no further evidence of bleaching of DOM by $\mathrm{NaClO}$.

\subsubsection{TChl-Specific Phytoplankton Absorption}

The relationship between $a_{\phi}(440)$ and TChl is affected by pigment packaging (cell size) and accessory pigments, the former of which has the greatest effect [4,59]. In Case 1 ocean waters, there is a general relationship between cell size and trophic state, with larger cells occurring at higher TChl values. Therefore, the $a_{\phi}$ to TChl ratio (or the specific absorption $a_{\phi}^{*}$ ) decreases with increasing TChl, due to pigment packaging, which is manifest by an exponential relationship between $a_{\phi}$ and TChl. Similarly, the influence of non-photosynthetic pigments relative to chl- $a$, measured as the ratio of blue to red phytoplankton absorption, tends to decrease as TChl increases. This also contributes to the effect. However, in coastal waters, accessory pigments, such as phaeopigments and phytoplankton size dynamics, are responsible for large variations in $a_{\phi}$ (e.g., $\left.[3,60]\right)$. The influence of phaeopigments is significant in both Loskop and Theewaterskloof (chl-a:TChl $\approx 0.5$ and 0.7 , respectively) and less so in Hartbeespoort (Figure 15). Therefore, it is expected that variable accessory pigments and size will also cause large variations in $a_{\phi}$ in lakes.

Figure 15. Frequency distribution of the chl- $a$ to TChl (chl- $a+$ pheo) ratio for each reservoir.

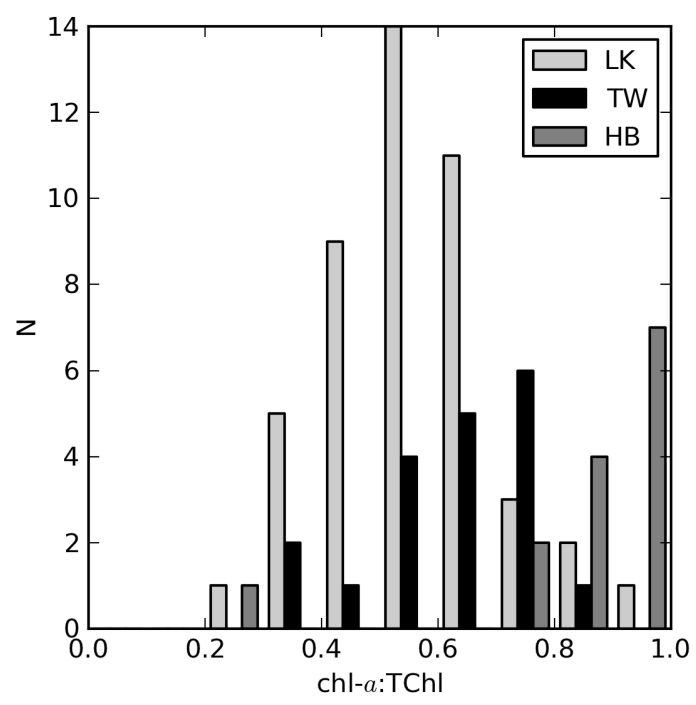


Figure 16. (A) $a_{\phi}$ versus $\mathrm{TChl}$ at $440 \mathrm{~nm}$ and (B) $675 \mathrm{~nm}$ showing the best fit line (-); (C) $a_{\phi}(442)$ versus $a_{\phi}(675)$; (D) $a_{\phi}(442): a_{\phi}(675)$ versus TChl; (E) $a_{\phi}^{*}$ versus $\mathrm{TChl}$ at $442 \mathrm{~nm}$ and (F) $675 \mathrm{~nm}$. Dotted lines show the fits from Case 1 marine waters [4]. The legend is the same in all panels. Note the log scales.
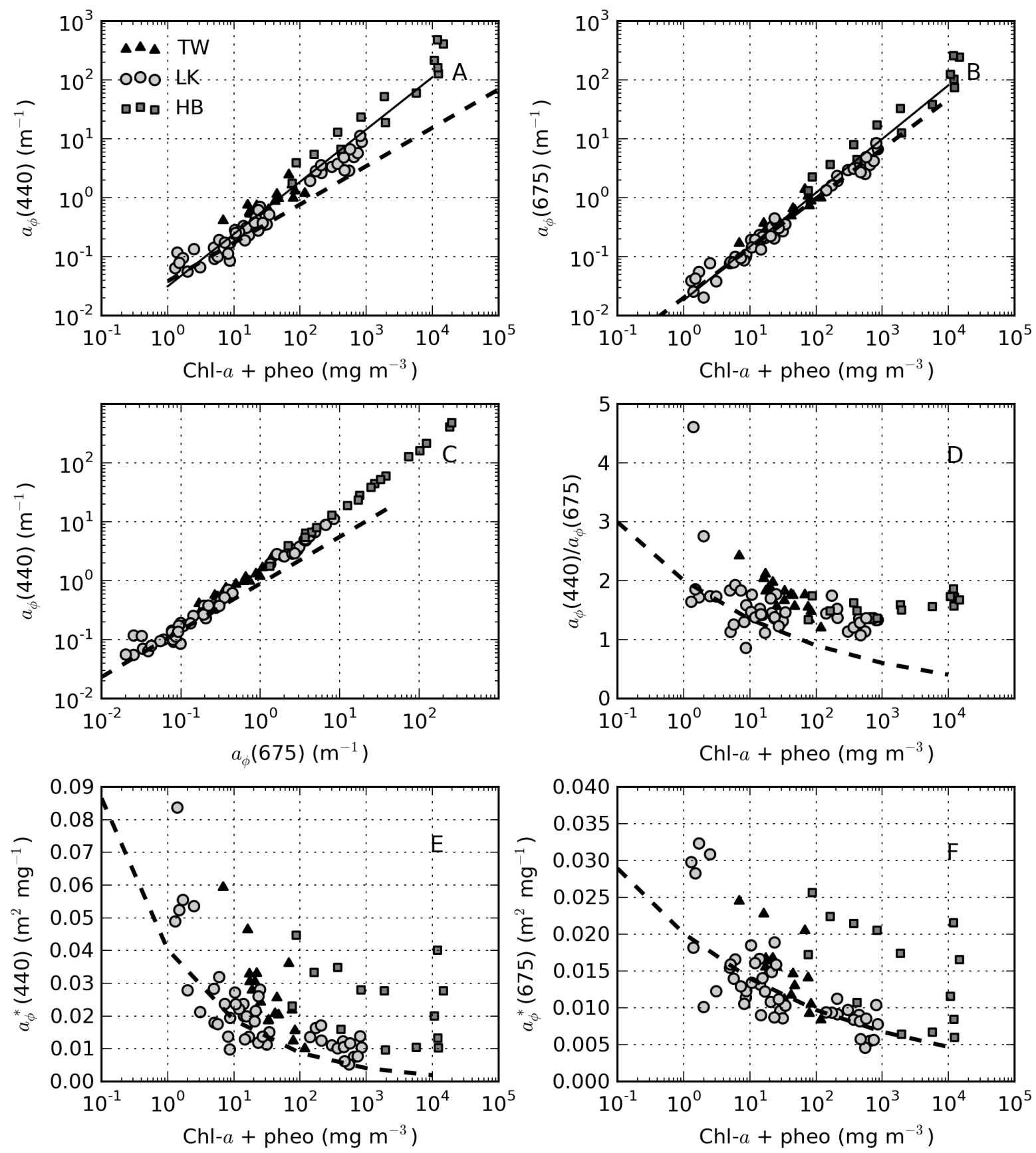

Figure 16A shows the relationship between $a_{\phi}(440)$ and TChl, which is best described by $a_{\phi}(440)=0.031 T C h l^{0.89}\left(r^{2}=0.95, \mathrm{~N}=82\right)$. For TChl $<$ approximately $30 \mathrm{mg} \cdot \mathrm{m}^{-3}$, the data are in general agreement with Case 1 estimates, after which they are positioned above the extrapolated line (maximum TChl value in Bricaud et al. [4] $=25 \mathrm{mg} \cdot \mathrm{m}^{-3}$ ). The reasons for the deviation are most easily explained by looking at each reservoir in turn. In Loskop, the explanation is not likely related to cell size (the package effect), since the dominant species is the large-celled $C$. hirundinella. A more 
plausible explanation is the presence of strong accessory pigments (Figure 15). The $a_{\phi}$ blue:red ratio decreases only slightly with increasing TChl values (Figure 16C,D), evidence of significant accessory pigment influence at high TChl values. This is not inside expectations for typical Case 1 waters. For $a_{\phi}(675)$, however, the data are in close agreement with Bricaud et al. [4], where the influence of accessory pigments is reduced $\left(a_{\phi}(675)=0.018 T C h l^{0.91}, r^{2}=0.97, \mathrm{~N}=82\right.$ ) (Figure 16B). Therefore, accessory pigments are the cause of large deviations from Case 1 results in the blue spectrum. The same explanation might be given for the same effect observed for Theewaterskloof data, since the phytoplankton assemblage is also generally dominated by a mix of large-celled species.

It is apparent in Figure 15A,B that the Hartbeespoort data are consistently above those of Theewaterskloof and Loskop. Accessory pigments alone cannot explain this large deviation from classical Case 1 results. A more likely cause is the small cell size of the dominant species, $M$. aeruginosa $(d=5 \mu \mathrm{m})$, leading to reduced pigment packaging. Although $M$. aeruginosa exists in colonial aggregations of large size, the affect on the bulk IOPs appears to be consistent with small cells. Despite the extremely high TChl values, accessory pigments also appear to have a significant impact in blue wavelengths (Figure 16C,D). Therefore, it is apparent that the M. aeruginosa blooms violate both of the assumptions of Case 1 waters, especially that cell size increases with trophic state. This is also likely to be the case for many other fresh waters dominated by small-celled cyanobacteria, resulting in wide inter- and intra-lake variability in $a_{\phi}^{*}$. The corresponding $a_{\phi}^{*}$ versus TChl scatter plots demonstrate this variability (Figure 16E,F). $a_{\phi}^{*}(440)$ values are expectedly larger than those typically observed in Case 1 waters; however, the agreement is better for $a_{\phi}^{*}(675)$ (for the reasons given above). The increase in $a_{\phi}^{*}$ induced by small cell size is evident for Hartbeespoort. The wide ranging $a_{\phi}^{*}$ values for TChl $>1,000 \mathrm{mg} \cdot \mathrm{m}^{-3}$ might be a result of the difficulty of measuring both absorption and TChl in "scum" conditions-methodological errors are prone to become greatly enlarged in both techniques. The lake-specific exponential fits for $a_{\phi}^{*}$ versus TChl are shown in Table 4.

Table 4. Exponential fit between $a_{\phi}^{*}$ and TChl at selected wavelengths for each reservoir.

\begin{tabular}{cccc}
\hline Reservoir & Power Fit & $\boldsymbol{r}^{\mathbf{2}}$ & $\mathbf{~ N}$ \\
\hline TW & $a_{\phi}^{*}(440)=0.129 T C h l^{-0.48}$ & 0.64 & 19 \\
TW & $a_{\phi}^{*}(675)=0.039 T C h l^{-0.29}$ & 0.52 & 19 \\
LK & $a_{\phi}^{*}(440)=0.039 T C h l^{-0.23}$ & 0.63 & 49 \\
LK & $a_{\phi}^{*}(675)=0.021 T C h l^{-0.17}$ & 0.62 & 49 \\
HB & $a_{\phi}^{*}(440)=0.050 T C h l^{-0.11}$ & 0.18 & 14 \\
HB & $a_{\phi}^{*}(675)=0.038 T C h l^{-0.14}$ & 0.28 & 14 \\
\hline
\end{tabular}

Figure 14 provides selected examples of $a_{\phi}^{*}$ spectra arranged by trophic class, as well as the mean for each reservoir. Table 5 gives statistics for $a_{\phi}^{*}(440)$ arranged by trophic class, as well as for the $M$. aeruginosa and $C$. hirundinella monospecific blooms. The statistics show that the mean value of $a_{\phi}^{*}(440)$ decreases from oligotrophic to hypertrophic classes (from 0.056 to $0.018 \mathrm{~m}^{2} \cdot \mathrm{mg}^{-1}$ ), in agreement with expectations. The variability (indicated by the standard deviation) also decreases with TChl (excluding the Hartbeespoort M.aeruginosa data). $a_{\phi}^{*}$ spectra from oligotrophic waters have spectra that occasionally slope upwards towards the blue (Figure 14A). This effect is likely related to strong 
accessory pigments at low TChl concentrations or possible DOM bleaching, in the case of Loskop. Meso-eutrophic waters associated with Loskop and Theewaterskloof typically have $a_{\phi}^{*}(440)$ values near $0.02 \mathrm{~m}^{2} \cdot \mathrm{mg}^{-1}$ and similar shapes, due the presence of large-celled dinoflagellates in both reservoirs (Figure 14B). Figure 14C,D shows large differences in magnitude and spectral pigmentation for the C. hirundinella and M.aeruginosa blooms (mean $a_{\phi}^{*}(440)=0.011$ and $0.024 \mathrm{~m}^{2} \cdot \mathrm{mg}^{-1}$, respectively). The wide variability of $a_{\phi}^{*}(440)$ for $M$. aeruginosa is most likely due to measurement difficulties associated with the extremely high biomass. These data represent the extrema of dinoflagellate and cyanobacteria dominance. The high variability in $a_{\phi}^{*}$ is related to the wide trophic range and variable phytoplankton populations in and between the reservoirs. This highlights the difficulty of applying generalized IOP models to lakes and the need for lake-trophic class and/or species-specific IOPs.

Table 5. General statistics for $a_{\phi}^{*}(440)\left(\mathrm{m}^{2} \cdot \mathrm{mg}^{-1}\right)$ according to trophic class and mono-specific blooms.

\begin{tabular}{lllllll}
\hline Trophic Class & Min. & Max. & Range & Mean \pm St. Dev. & Median & N \\
\hline Oligotrophic $(\mathrm{TChl}<5)$ & 0.021 & 0.084 & 0.062 & $0.056 \pm 0.020$ & 0.051 & 8 \\
Oligotrophic $(\mathrm{TChl}<10)$ & 0.010 & 0.084 & 0.074 & $0.035 \pm 0.021$ & 0.028 & 16 \\
Mesotrophic $(10<\mathrm{TChl}<20)$ & 0.013 & 0.046 & 0.034 & $0.025 \pm 0.009$ & 0.024 & 12 \\
Eutrophic $(20<\mathrm{TChl}<30)$ & 0.012 & 0.033 & 0.021 & $0.022 \pm 0.007$ & 0.022 & 11 \\
Hypertrophic $(\mathrm{TChl}>30)$ & 0.005 & 0.045 & 0.039 & $0.018 \pm 0.010$ & 0.015 & 42 \\
C. hirundinella $(\mathrm{TCh}>30)$ & 0.005 & 0.017 & 0.012 & $0.011 \pm 0.003$ & 0.011 & 17 \\
M. aeruginosa $(\mathrm{TChl}>30)$ & 0.010 & 0.045 & 0.035 & $0.024 \pm 0.011$ & 0.023 & 15 \\
\hline
\end{tabular}

\subsubsection{Phycocyanin-Specific Phytoplankton Absorption}

Phycocyanin pigment was determined for samples where cyanobacteria made up a significant proportion of the phytoplankton population. PC might give a better indication of cyanobacterial biomass than chl- $a$, given that it is the primary light harvesting pigment in cyanobacteria [61]. It is also a very distinctive pigment that may be used to discriminate cyanobacteria from other algal populations [62]. The relationship between PC and chl- $a$ is best described by $P C=8.7 \times$ chla $^{0.74}$ for Hartbeespoort $\left(r^{2}=0.87, \mathrm{~N}=34\right)$ and $P C=4.70 \times$ chla $a^{0.4199}$ for Theewaterskloof $\left(r^{2}=0.32, \mathrm{~N}=19\right)$ (Figure 17A). The Theewaterskloof data are from a mixed algae/cyanobacteria population. Therefore, chl- $a$ originates from algae, as well as cyanobacteria, resulting in a reduced PC:chl- $a$ ratio, as observed in Figure 17A. In contrast, the Hartbeespoort data are from a monospecific $M$. aeruginosa bloom. These data demonstrate that as cyanobacterial biomass increases, the production of PC is reduced relative to chl- $a$. A similar effect is observed in Hartbeespoort for accessory pigments allophycocyanin $\left(A P C=11.2 \times\right.$ chla $^{0.59}$, $\left.r^{2}=0.68, \mathrm{~N}=34\right)$ and pheophytin $\left(P h e o=0.16 \times c h l a^{0.9522}, r^{2}=0.95, \mathrm{~N}=38\right)$. Accessory pigments are modulated either by high light and nutrient exposure (e.g., [63]) or through other physiological processes reflected by changes in gross biomass.

The equations for the PC:chl-a ratio versus chl-a were derived mathematically from the power-law function and are, therefore, not a result of "spurious correlation" [64]. According to the relationship, $8.7 \mathrm{chla}^{-0.26}$ (Figure 17B), the PC:chl- $a$ ratio decreases from three at chl- $a=100 \mathrm{mg} \cdot \mathrm{m}^{-3}$ to 0.7 at chl- $a=10,000 \mathrm{mg} \cdot \mathrm{m}^{-3}$ in Hartbeespoort. This effect might be related to nitrogen limitation as cell 
abundance increases [65]; however, nutrient data acquired simultaneously reveal no shortage of total nitrogen (or other nutrients) associated with reduced PC:chl- $a$ ratios (Figure 17C). An alternative explanation is that phycobilipigment production is reduced in high light, shallow mixed surface scum layers $[63,66]$ or in fast growth scenarios. While a precise explanation for this effect remains somewhat unknown, the observation has some important implications for extremely high biomass and surface scum scenarios. If the production of accessory pigment PC is reduced relative to chl- $a$ in surface scums, then chl- $a$ might be a better indicator of biomass in these extreme conditions. Secondly, when interpreting measurements made in surface scums, the reduced accessory pigment production might be used to explain some unusual effects in the PC-specific absorption.

Figure 17. (A) chl-a versus PC showing the best fit lines for HB and TW; (B) The PC:chl- $a$ ratio versus chl- $a$ showing best fit lines for $\mathrm{HB}$ and TW; (C) The PC:chl- $a$ ratio versus total nitrogen concentration; (D) $a_{p c}(620)$ versus PC showing the power-law best fit line; (E) the PC:chl- $a$ ratio versus $a_{p c}^{*}(620)$; (F) TChl- $a$ versus $a_{p c}^{*}(620)$ showing the power-law best fit line for HB. The legend is the same in all plots. Note the log scales.
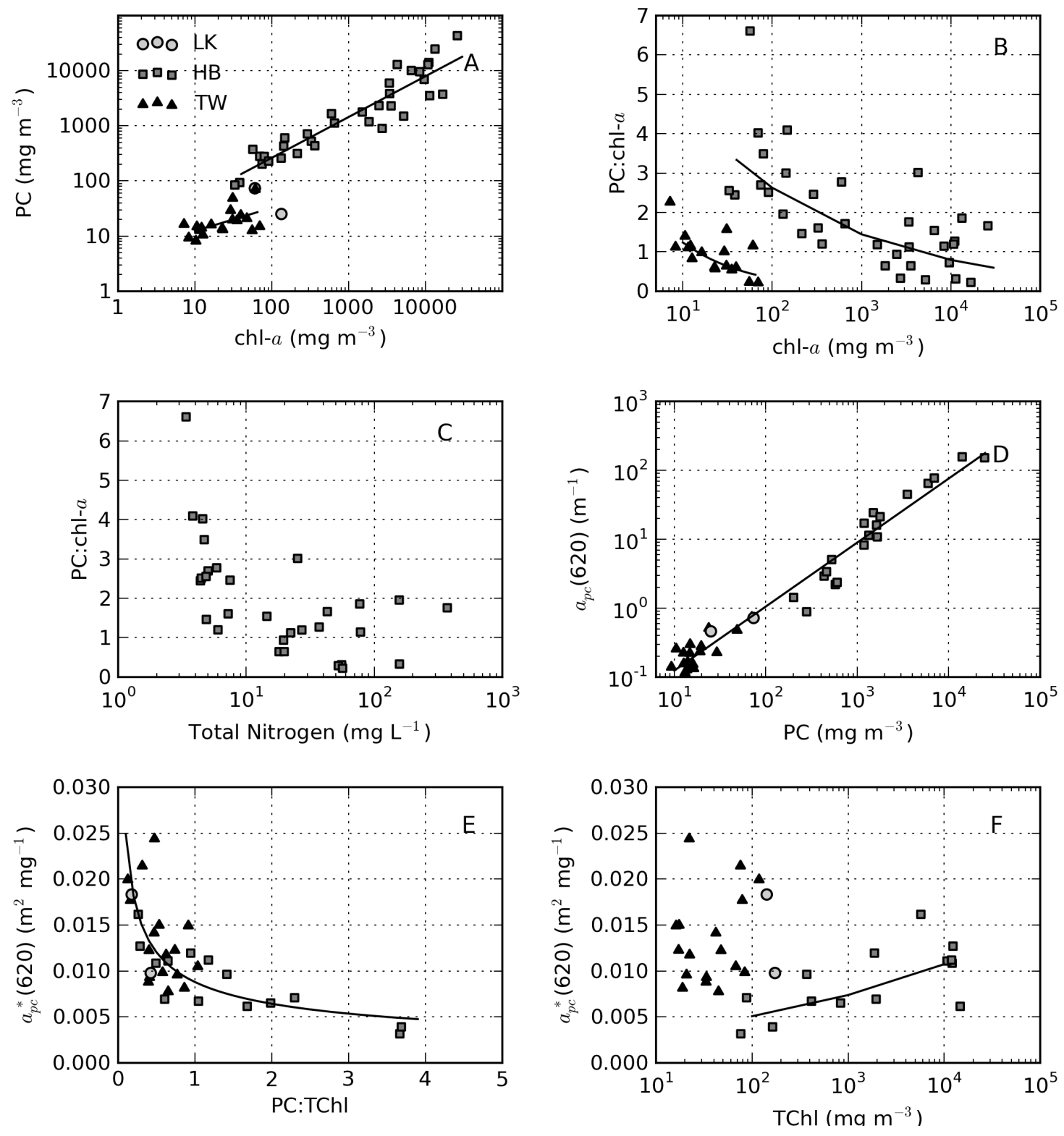
$a_{p c}(620)$ and PC are related by $a_{p c}(620)=0.0146 \times P C^{0.929}\left(r^{2}=0.97, \mathrm{~N}=36\right)$. Clustering in the data around $10-20 \mathrm{mg} \mathrm{m}^{-3} \mathrm{PC}$ resulted in a reduced coefficient of determination for Theewaterskloof alone $\left(r^{2}=0.61\right)$, while PC varies by more than three orders of magnitude in Hartbeespoort $\left(r^{2}=0.93\right)$. The reduced goodness of fit in Theewaterskloof is likely the result of a strong influence near $620 \mathrm{~nm}$ of chl- $c$ and chl- $b$ from diatoms and chlorophytes. This is substantiated by relatively low PC:TChl ratios in Theewaterskloof (median $=0.53$, see Figure 17E). An inverse relationship is present between the PC:TChl ratio and $a_{p c}^{*}(620)\left(y=0.0088 x^{-0.451}, r^{2}=0.63, \mathrm{~N}=31\right.$, Figure 17E), similar to that observed by Simis et al. [12]. The variability in $a_{p c}^{*}(620)$ is typically attributed to the contribution of cyanobacteria to the total phytoplankton population [48]. While this is probably the case for Theewaterskloof, the variability observed in Hartbeespoort can only be caused by biomass related variable accessory pigment $(\mathrm{PC})$ production. Therefore, $a_{p c}^{*}(620)$ varies not only according to the relative contributions of cyanobacteria/algae, but also with physiological processes related to biomass affecting the PC:chl- $a$ ratio within monospecific blooms (Figure 17B). Figure 17F provides some further evidence for biomass-induced changes in $a_{p c}^{*}(620)$ in Hartbeespoort. A positive correlation is present between TChl and $a_{p c}^{*}(620)\left(y=0.0024 x^{0.1627}, r^{2}=0.48, \mathrm{~N}=14\right)$. No such relationship is apparent for Theewaterskloof. Therefore, the variability in $a_{\phi}^{*}(620)$ in Hartbeespoort appears to be caused, at least partially, by biomass-related phenomena related to reduced PC production in high light surface scum conditions.

The value for in vivo $a_{p c}^{*}(620)$ was recently experimentally determined as $0.007 \mathrm{~m}^{2} \cdot \mathrm{mg}^{-1}$ for a wide variety of cultured cyanobacteria [67]. The median values for $a_{p c}^{*}(620)$ determined in Theewaterskloof and Hartbeespoort are 0.0122 and $0.0085 \mathrm{~m}^{2} \cdot \mathrm{mg}^{-1}$, respectively. This is within the range of those previously measured in natural populations [12]. For PC:TChl ratios $>0.5$ the value in Theewaterskloof is reduced to $0.010 \mathrm{~m}^{2} \cdot \mathrm{mg}^{-1}$. For Hartbeespoort data not affected by large biomass effects, i.e., TChl $<1,000 \mathrm{mg} \cdot \mathrm{m}^{-3}$, the median value for $a_{p c}^{*}(620)$ is 0.0067 , and the mean is $0.0072 \mathrm{~m}^{2} \cdot \mathrm{mg}^{-1}$, which is nearly identical to that of Simis et al. [48] and Simis and Kauko [67]. This also demonstrates that the method for PC extraction used in this study is probably efficient.

\subsection{Absorption Budgets}

The ternary plots in Figure 18 show the relative contributions by gelbstoff, phytoplankton and tripton towards the total absorption budget of each reservoir. At $442 \mathrm{~nm}$ (Figure 18A), there is a strong influence by all components. The clustering of data from Hartbeespoort towards the phytoplankton apex is indicative of an overwhelming dominance of phytoplankton absorption. Therefore, Hartbeespoort waters (or the M. aeruginosa bloom) might strictly be classified as Case 1, i.e., phytoplankton are the dominant contributor to absorption [68]. Similarly, the cluster of Loskop data from the $C$. hirundinella bloom towards the phytoplankton apex might also be classified as Case 1: more than $80 \%$ of the absorption is attributed to phytoplankton. It should be noted, however, that while strictly speaking, these can be classified as Case 1 waters, the reflectance features of Case 1 green waters described by Morel and Prieur [68] will be substantially different to those described here. This might mean that some complexities regarding remote sensing applications are removed, and the blooms of M.aeruginosa and $C$. hirundinella can essentially be treated as "cultures", (i.e., the minimal influence of constituents 
other than phytoplankton). This provides an opportunity for remote sensing algorithms that take advantage of a signal originating primarily from phytoplankton in eutrophic waters. One such example is the maximum peak height algorithm [62] designed for use with the Medium Resolution Imaging Spectrometer (MERIS) red wavebands, which is derived from datasets obtained from Hartbeespoort and Loskop.

Figure 18. Ternary plots showing the relative contributions of gelbstoff, tripton and phytoplankton to absorption at (A) $442 \mathrm{~nm}$ and (B) $675 \mathrm{~nm}$.

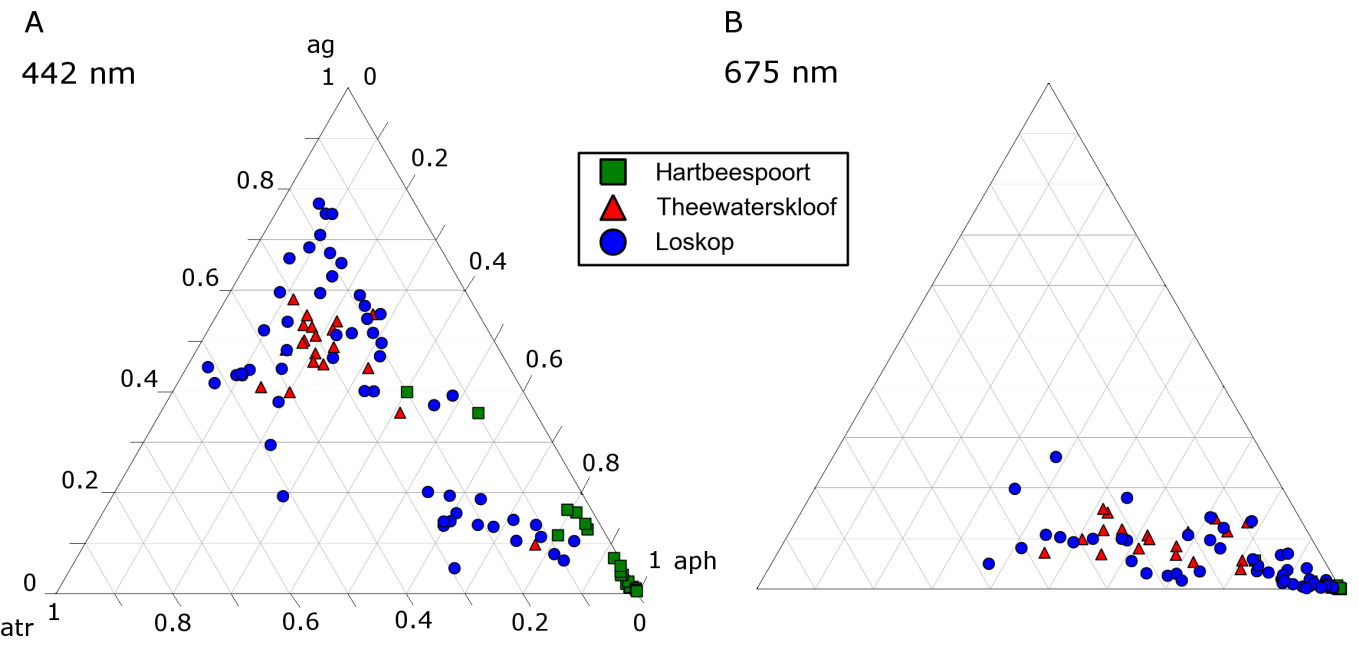

The remainder of the Loskop data is typically dominated by gelbstoff (40\%-80\%) with lesser contributions from phytoplankton $(<50 \%)$ and tripton $(20 \%-50 \%)$ towards absorption. Absorption in Theewaterskloof is generally comprised of 50\% gelbstoff, $20 \%$ phytoplankton and $30 \%$ tripton. These fall into the classification of Case 2 or optically complex waters. At $675 \mathrm{~nm}$, Figure 18B, the data are expectedly clustered towards the phytoplankton apex, which results from the reduced influence of tripton and gelbstoff absorption in red wavelengths. This shift due to the spectral characteristics of the absorption components is visible at various wavebands of the upcoming Sentinal 3 and past MERIS sensors (Figure 19). The majority of the water encountered in the reservoirs are complex from an optical perspective, requiring remote sensing applications, taking into account the absorption characteristics of all water constituents presented here. A recent study by Matthews and Bernard [14] demonstrates an approach utilizing IOPs derived from this study for radiative transfer modeling and the derivation of remote sensing algorithms.

The analysis conducted here is based on sampling campaigns conducted over a short time period and at various times of the year. There is significant seasonal variability in the contribution of phytoplankton towards the absorption budgets, with the maximum being reached in later summer and the minimum during winter (Matthews, unpublished data). This has large implications for remote sensing applications. For example, Hartbeespoort can shift from hypertrophic surface scum conditions during late summer to an oligotrophic clear-water phase during winter (Matthews, unpublished data). The gelbstoff component generally has little seasonal variability, but will increasingly contribute towards the absorption budget during such clear-water phases. Therefore, remote sensing approaches utilizing IOP models capable of simulating a wide range of water conditions are required for routine 
derivation of water information products. The specific IOPs derived here can be used in such models to simulate both clear water and hypertrophic phases and for training of radiative transfer-based algorithms (e.g., Matthews and Bernard [14]).

Figure 19. Ternary plots showing the relative contributions of gelbstoff, tripton and phytoplankton to absorption at various wavelengths of the Sentinal 3 and MERIS sensors.
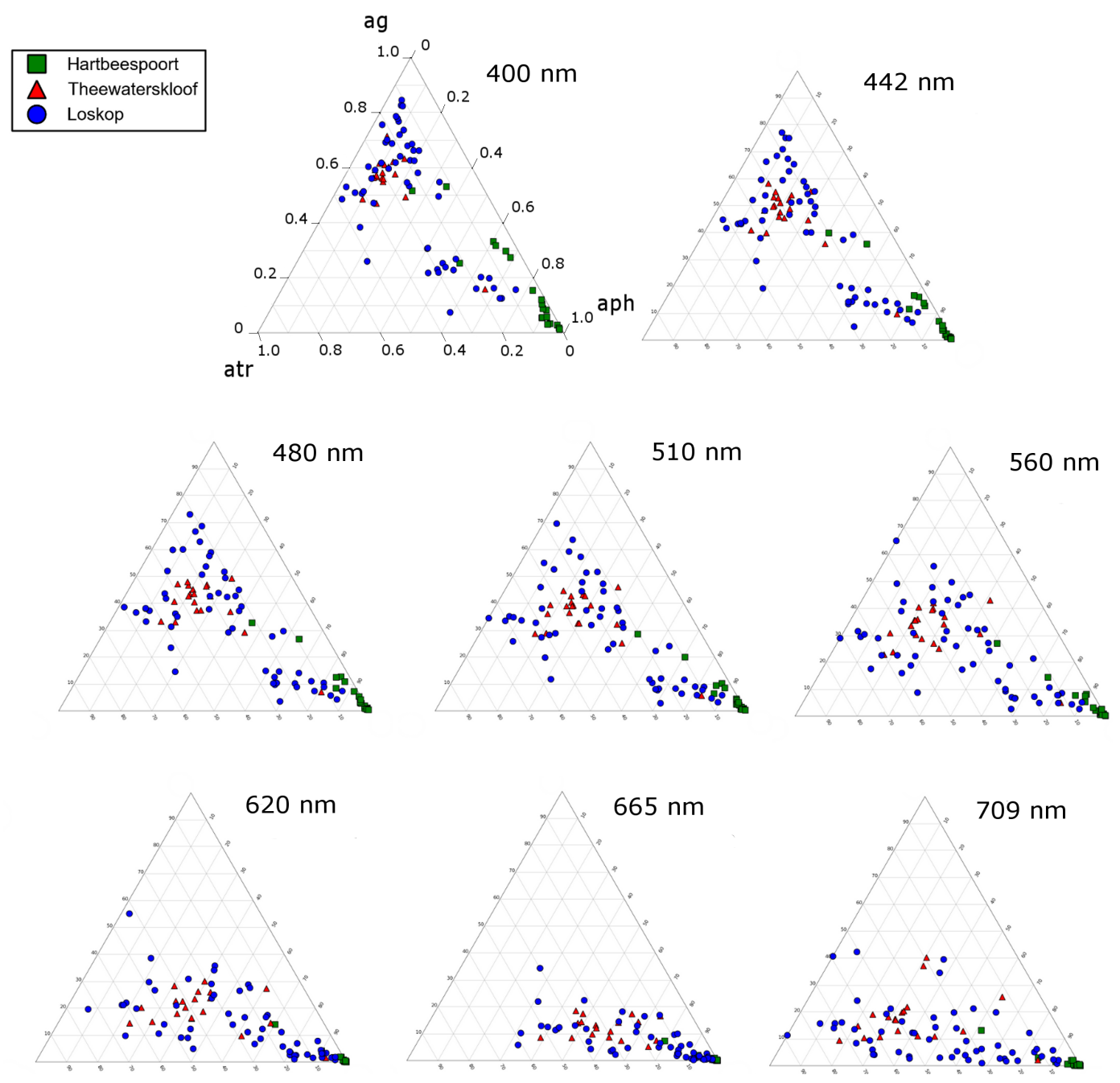

\section{Conclusions}

The specific inherent optical properties (SIOPs) of phytoplankton, gelbstoff and tripton have been determined for three small South African reservoirs for use in water remote sensing applications. The study adds to the limited knowledge of SIOPs in diverse inland waters, especially those that are hypertrophic. The absorption properties of the reservoirs are extremely variable, highlighting the need for lake, trophic class and/or species-specific IOP models. Relationships between the absorption components and biogeochemical parameters are in many instances reservoir-specific. As for coastal waters, accessory pigments and variable phytoplankton size (package effect) are responsible for large variations in $a_{\phi}^{*}$ in inland waters. In particular, high biomass populations of small-celled cyanobacteria cause a breakdown in the conventional relationship between cell size and trophic state in inland waters. 
The data from $M$. aeruginosa blooms provide new insight into the absorption properties and pigmentation of cyanobacterial surface scums. An observed reduction in accessory pigment production in surface scums suggests that chl- $a$ might be a better indicator of biomass than phycocyanin (PC) in these extreme cases. $a_{p c}^{*}(620)$ was nearly identical to that determined experimentally by Simis and Kauko [67] $=0.007 \mathrm{~m}^{2} \cdot \mathrm{g}^{-1}$. The variability in $a_{p c}^{*}(620)$ could be attributed both to variable algal/cyanobacteria composition and to biomass-related effects. There was evidence that the hot methanol QFT technique leads to under-extraction of PC by $15 \%-20 \%$, even when no discernible absorption features are present in the tripton absorption spectrum.

A new method devised for determining the value of the chl- $a$ to dry mass conversion coefficient, $\beta$, produced values for $a_{t r}^{*}$ in general agreement with inland and mineral-rich marine waters. $\beta$ was found to significantly influence $a_{t r}^{*}$. The presence of heterotrophic bacteria in high biomass M. aeruginosa blooms caused conventional methods for determining tripton absorption to fail. Therefore, alternative methods are needed for determining tripton absorption in hypertrophic conditions.

In conclusion, the use of the SIOPs derived here will advance the application of remote sensing in small, hypertrophic inland waters. Similar studies should be performed in diverse inland waters representative of other geographical regions of the world where data are lacking. The use of these and similar data in bio-optical models will contribute to the ongoing development of globally applicable remote sensing products for inland waters.

\section{Acknowledgments}

The authors gratefully acknowledge the following people who assisted with various aspects of data collection: Nobuhle Majozi, Marie Smith, Heidi van Deventer, Russell Main, Hayley Evers-King, Trevor Probyn and Paul Oberholster. The authors also thank the Department of Water Affairs, Loskop Nature Reserve and the Theewaterskloof Sports Club. The work was carried out under the Council for Scientific and Industrial Research (CSIR) research project, Safe Waters Earth Observation Systems. For funding M.W.M.: CSIR and the University of Cape Town.

\section{Conflicts of Interest}

The authors declare no conflict of interest.

\section{References}

1. Oki, K. Why is the ratio of reflectivity effective for chlorophyll estimation in the lake water? Remote Sens. 2010, 2, 1722-1730.

2. Bricaud, A.; Babin, M.; Claustre, H.; Ras, J.; Tièche, F. Light absorption properties and absorption budget of Southeast Pacific waters. J. Geophys. Res. 2010, 115, C08009.

3. Babin, M.; Stramski, D.; Ferrari, G.M.; Claustre, H.; Bricaud, A.; Obolensky, G.; Hoepffner, N. Variations in the light absorption coefficients of phytoplankton, nonalgal particles, and dissolved organic matter in coastal waters around Europe. J. Geophys. Res.-Oceans 2003, 108, 4:1-4:20. 
4. Bricaud, A.; Babin, M.; Morel, A.; Claustre, H. Variability in the chlorophyll-specific absorption coefficients of natural phytoplankton: Analysis and parameterization. J. Geophys. Res. 1995, $100,13321-13332$.

5. Le, C.; Hu, C.; English, D.; Cannizzaro, J.; Chen, Z.; Kovach, C.; Anastasiou, C.J.; Zhao, J.; Carder, K.L. Inherent and apparent optical properties of the complex estuarine waters of Tampa Bay: What controls light? Estuar. Coast. Shelf Sci. 2013, 117, 54-69.

6. Campbell, G.; Phinn, S.R.; Daniel, P. The specific inherent optical properties of three sub-tropical and tropical water reservoirs in Queensland, Australia. Hydrobiologia 2010, 658, 233-252.

7. Zhang, Y.L.; Liu, M.L.; Wang, X.; Zhu, G.W.; Chen, W.M. Bio-optical properties and estimation of the optically active substances in Lake Tianmuhu in summer. Int. J. Remote Sens. 2009, 30, 2837-2857.

8. Perkins, M.; Effler, S.W.; Strait, C.; Zhang, L. Light absorbing components in the Finger Lakes of New York. Fundam. Appl. Limnol./Arch. Hydrobiol. 2009, 173, 305-320.

9. Binding, C.; Jerome, J.; Bukata, R.; Booty, W. Spectral absorption properties of dissolved and particulate matter in Lake Erie. Remote Sens. Environ. 2008, 112, 1702-1711.

10. Belzile, C.; Vincent, W.F.; Howard-Williams, C.; Hawes, I.; James, M.R.; Kumagai, M.; Roesler, C.S. Relationships between spectral optical properties and optically active substances in a clear oligotrophic lake. Water Resour. Res. 2004, doi: 10.1029/2004WR003090.

11. Oberholster, P.J.; Botha, A.M.; Cloete, T.E. An overview of toxic freshwater cyanobacteria in South Africa with special reference to risk, impact and detection by molecular marker tools. Biokemistri 2005, 17, 57-71.

12. Simis, S.G.H.; Peters, S.W.M.; Gons, H.J. Remote sensing of the cyanobacterial pigment phycocyanin in turbid inland water. Limnol. Oceanogr. 2005, 50, 237-245.

13. Ruizverdu, A.; Simis, S.; Dehoyos, C.; Gons, H.; Penamartinez, R. An evaluation of algorithms for the remote sensing of cyanobacterial biomass. Remote Sens. Environ. 2008, 112, 3996-4008.

14. Matthews, M.W.; Bernard, S. Using a two-layered sphere model to investigate the impact of gas vacuoles on the inherent optical properties of M. aeruginosa. Biogeosci. Discuss. 2013, 10, 1-48.

15. Van Ginkel, C.; Silberbauer, M. Temporal trends in total phosphorus, temperature, oxygen, chlorophyll a and phytoplankton populations in Hartbeespoort Dam and Roodeplaat Dam, South Africa, between 1980 and 2000. Afr. J. Aquat. Sci. 2007, 32, 63-70.

16. Zohary, T.; Pais-Madeira, A.; Robarts, R.; Hambright, K. Interannual phytoplankton dynamics of a hypertrophic African lake. Arch. Hydrobiol. 1996, 136, 105-126.

17. Scott, W.; Seaman, M.; Connell, A.; Kohlmeyer, S.; Toerien, D. The limnology of some South African impoundments I. The physico-chemical limnology of Hartbeespoort Dam. J. Limnol. Soc. South. Afr. 1977, 3, 43-58.

18. Zohary, T. Hyperscums of the cyanobacterium Microcystis aeruginosa in a hypertrophic lake (Hartbeespoort Dam, South Africa). J. Plankton Res. 1985, 7, 399-409.

19. Robarts, R.; Zohary, T. The influence of temperature and light on the upper limit of Microcystis aeruginosa production in a hypertrophic reservoir. J. Plankton Res. 1992, 14, 235.

20. Robarts, A.R.D.; Zohary, T.; Robarts, R.D. Microcystis aeruginosa and underwater light attenuation in a hypertrophic lake (Hartbeespoort Dam, South Africa). J. Ecol. 1984, 72, 1001-1017. 
21. Dabrowski, J. Water Quality, Metal Bioaccumulation and Parasite Communities of Oreochromis Mossambicus in Loskop Dam, Mpumalanga, South Africa. M.Sc. Thesis, University of Pretoria, Pretoria, South Africa, 2012.

22. Oberholster, P.J.; Myburgh, J.G.; Ashton, P.J.; Botha, A.M. Responses of phytoplankton upon exposure to a mixture of acid mine drainage and high levels of nutrient pollution in Lake Loskop, South Africa. Ecotoxicol. Environ. Saf. 2010, 73, 326-335.

23. Walmsley, R.; Bruwer, C. Water transparency characteristics of South African impoundments. $J$. Limnol. Soc. South. Afr. 1980, 6, 69-76.

24. Sartory, D.P.; Grobbelaar, J.U. Extraction of chlorophyll a from freshwater phytoplankton for spectrophotometric analysis. Hydrobiologia 1984, 114, 177-187.

25. Sarada, R.; Pillai, M.G.; Ravishankar, G. Phycocyanin from Spirulina sp: Influence of processing of biomass on phycocyanin yield, analysis of efficacy of extraction methods and stability studies on phycocyanin. Process Biochem. 1999, 34, 795-801.

26. Stewart, D.E.; Farmer, F.H. Extraction, and quantitation of phycobiliprotein pigments from phototrophic plankton. Limnol. Oceanogr. 1984, 29, 392-397.

27. Wyman, M.; Fay, P. Underwater light climate and the growth and pigmentation of planktonic blue-green algae (Cyanobacteria) II. The influence of light quality. Proc. R. Soc. B Biol. Sci. 1986, 227, 381-393.

28. Zhu, Y.; Chen, X.B.; Wang, K.B.; Li, Y.X.; Bai, K.Z.; Kuang, T.Y.; Ji, H.B. A simple method for extracting C-phycocyanin from Spirulina platensis using Klebsiella pneumoniae. Appl. Microbiol. Biotechnol. 2007, 74, 244-248.

29. Viskari, P.J.; Colyer, C.L. Rapid extraction of phycobiliproteins from cultured cyanobacteria samples. Anal. Biochem. 2003, 319, 263-271.

30. Beutler, M. Spectral Fluorescence of Chlorophyll and Phycobilins as an in situ Tool of Phytoplankton Analysis Models, Algorithms and Instruments. Ph.D. Thesis, University of Kiel, Kiel, Germany, 2003.

31. Bennett, A.; Bogorad, L. Complementary chromatic adaptation in a filamentous blue-green alga. J. Cell Biol. 1973, 58, 419-35.

32. Environmental Protection Agency (EPA). Methods for Chemical Analysis of Water and Wastes; Technical Report 600479020; United States Environmental Protection Agency: Cincinnati, OH, USA, 1983.

33. Giardino, C.; Brando, V.E.; Dekker, A.G.; Strömbeck, N.; Candiani, G. Assessment of water quality in Lake Garda (Italy) using Hyperion. Remote Sens. Environ. 2007, 109, 183-195.

34. Dekker, A.G.; Vos, R.J.; Peters, S.W.M. Comparison of remote sensing data, model results and in situ data for total suspended matter (TSM) in the southern Frisian lakes. Sci. Total Environ. 2001, 268, 197-214.

35. Hoogenboom, H.J.; Dekker, A.G.; Althuis, I.A. Simulation of AVIRIS sensitivity for detecting chlorophyll over coastal and inland waters. Remote Sens. Environ. 1998, 65, 333-340.

36. Gons, H.J.; Burger-wiersma, T.; Otten, J.H.; Rijkeboer, M. Coupling of phytoplankton and detritus in a shallow , eutrophic lake (Lake Loosdrecht, The Netherlands). Hydrobiologia 1992, 233, 51-59. 
37. Zhang, Y.; Liu, M.; Qin, B.; van der Woerd, H.J.; Li, J.; Y, L. Modeling remote-sensing reflectance and retrieving chlorophyll-a concentration in extremely turbid case-2 waters (Lake Taihu, China). IEEE Trans. Geosci. Remote Sens. 2009, 47, 1937-1948.

38. Desortová, B. Relationship between chlorophyll-a concentration and phytoplankton biomass in several reservoirs in Czechoslovakia. Int. Revue Ges. Hydrobiol. 1981, 66, 153-169.

39. Reynolds, C.S. The Ecology of Phytoplankton; Cambridge University Press: New York, NY, USA, 2006.

40. Wen, Y.H. Contribution of bacterioplankton, phytoplankton, zooplankton and detritus to organic sestin carbon load in a Changjian floodplain lake (China). Arch. Hydrobiol. 1992. 126, 213-238.

41. van Valkenburg, S.; Jones, J.K.; Heinle, D.R. A comparison by size class and volume of detritus versus phytoplankton in Chesapeake Bay. Estuar. Coast. Mar. Sci. 1978, 6, 569-582.

42. Mitchell, B.G.; Kahru, M.; Wieland, J.; Stramska, M. Chapter 4. Determination of Spectral Absorption Coefficients of Particles, Dissolved Material and Phytoplankton for Discrete Water Samples. In Ocean Optics Protocols For Satellite Ocean Color Sensor Validation, Revision 4, Volume IV: Inherent Optical Properties: Instruments, Characterizations, Field Measurements and Data Analysis Protocols; Mueller, J.L., Fargion, G.S., McClain, C.R., Eds.; National Aeronautical and Space Administration: Greenbelt, MD, USA, 2003.

43. Roesler, C. Theoretical and experimental approaches to improve the accuracy of particulate absorption coefficients derived from the quantitative filter technique. Limnol. Oceanogr. 1998, $43,1649-1660$.

44. Zhang, Y.; Liu, M.; van Dijk, M.A.; Zhu, G.; Gong, Z.; Li, Y.; Qin, B. Measured and numerically partitioned phytoplankton spectral absorption coefficients in inland waters. J. Plankton Res. 2008, 31, 311-323.

45. Ferrari, G.M.; Tassan, S. A method using chemical oxidation to remove light absorption by phytoplankton pigments. J. Phycol. 1999, 35, 1090-1098.

46. Ferrari, G.M.; Tassan, S. A method for the experimental determination of light absorption by aquatic heterotrophic bacteria. J. Plankton Res. 1998, 20, 757-766.

47. Bricaud, A.; Morel, A.; Prieur, L. Absorption by dissolved organic matter of the sea (yellow substance) in the UV and visible domains. Limnol. Oceanogr. 1981, 26, 43-53.

48. Simis, S.G.H.; Ruiz-Verdu, A.; Dominguez-Gomez, J.A.; Pena-Martinez, R.; Peters, S.W.M.; Gons, H.J. Influence of phytoplankton pigment composition on remote sensing of cyanobacterial biomass. Remote Sens. Environ. 2007, 106, 414-427.

49. Kirk, J.T.O. Light and Photosynthesis in Aquatic Ecosystems; Cambridge University Press: Bristol, UK, 1994; p. 509.

50. Van Ginkel, C.E.; Hohls, B.C.; Vermaak, E. A Ceratium hirundinella (O.F. Müller) bloom in Hartbeespoort Dam, South Africa. Water SA 2001, 27, 269-276.

51. Hart, R.C.; Wragg, P.D. Recent blooms of the dinoflagellate Ceratium in Albert Falls Dam (KZN): History, causes, spatial features and impacts on a reservoir ecosystem and its zooplankton. Water SA 2009, 35, 455-468. 
52. Estapa, M.L.; Boss, E.; Mayer, L.M.; Roesler, C.S. Role of iron and organic carbon in mass-specific light absorption by particulate matter from Louisiana coastal waters. Limnol. Oceanogr. 2012 , 57, 97-112.

53. Sommaruga, R.; Robarts, R.D. The significance of autotrophic and heterotrophic picoplankton in hypertrophic ecosystems. FEMS Microbiol. Ecol. 1997, 24, 187-200.

54. Stramski, D.; Babin, M.; Wozniak, S.B. Variations in the optical properties of terrigenous mineral-rich particulate matter suspended in seawater. Limnol. Oceanogr. 2007, 52, 2418-2433.

55. Babin, M.; Stramski, D. Variations in the mass-specific absorption coefficient of mineral particles suspended in water. Limnol. Oceanogr. 2004, 49, 756-767.

56. Ibelings, B.W.; Kroon, B.M.A.; Mur, L.R. Acclimation of photosystem II in a cyanobacterium and a eukaryotic green alga to high and fluctuating photosynthetic photon flux densities, simulating light regimes induced by mixing in lakes. New Phytol. 1994, 128, 407-424.

57. Schluter, L.; Lauridsen, T.L.; Krogh, G.; Jorgensen, T. Identification and quantification of phytoplankton groups in lakes using new pigment ratios-A comparison between pigment analysis by HPLC and microscopy. Freshw. Biol. 2006, 51, 1474-1485.

58. Laurion, I.; Lami, A.; Sommaruga, R. Distribution of mycosporine-like amino acids and photoprotective carotenoids among freshwater phytoplankton assemblages. Aquatic Microb. Ecol. 2002, 26, 283-294.

59. Bricaud, A.; Claustre, H.; Ras, J.; Oubelkheir, K. Natural variability of phytoplanktonic absorption in oceanic waters: Influence of the size structure of algal populations. J. Geophys. Res. 2004, 109, $1-12$.

60. Blondeau-Patissier, D.; Brando, V.E.; Oubelkheir, K.; Dekker, A.G.; Clementson, L.A.; Daniel, P. Bio-optical variability of the absorption and scattering properties of the Queensland inshore and reef waters, Australia. J. Geophys. Res. 2009, 114, C05003.

61. Ahn, C.Y.; Joung, S.H.; Yoon, S.K.; Oh, H.M. Alternative alert system for cyanobacterial bloom, using phycocyanin as a level determinant. J. Microbiol. 2007, 45, 98-104.

62. Matthews, M.W.; Bernard, S.; Robertson, L. An algorithm for detecting trophic status (chlorophyll-a), cyanobacterial-dominance, surface scums and floating vegetation in inland and coastal waters. Remote Sens. Environ. 2012, 124, 637-652.

63. Deblois, C.P.; Marchand, A.; Juneau, P. Comparison of photoacclimation in twelve freshwater photoautotrophs (chlorophyte, bacillaryophyte, cryptophyte and cyanophyte) isolated from a natural community. PLoS One 2013, 8, 1-14.

64. Berges, J.A. Ratios, regression statistics, and "spurious" correlations. Limnol. Oceanogr. 1997, 42, 1006-1007.

65. Schwarz, S.; Grossman, A.R. A response regulator of cyanobacteria integrates diverse environmental signals and is critical for survival under extreme conditions. Proc. Natl. Acad. Sci. USA 1998, 95, 11008-11013.

66. Raps, S.; Kycia, J.H.; Ledbetter, M.C.; Siegelman, H.W. Light intensity adaptation and phycobilisome composition of microcystis aeruginosa. Plant Physiol. 1985, 79, 983-987.

67. Simis, S.G.; Kauko, H.M. In vivo mass-specific absorption spectra of phycobilipigments through selective bleaching. Limnol. Oceanogr. Methods 2012, 10, 214-226. 
68. Morel, A.; Prieur, L. Analysis of variations in ocean color. Limnol. Oceanogr. 1977, 22, 709-722. 69. Simis, S. Personal Communication, 2013.

(C) 2013 by the authors; licensee MDPI, Basel, Switzerland. This article is an open access article distributed under the terms and conditions of the Creative Commons Attribution license (http://creativecommons.org/licenses/by/3.0/). 